\title{
Epidemiologic studies of modifiable factors associated with cognition and dementia: systematic review and meta-analysis
}

\author{
May A Beydoun ${ }^{1 *}$, Hind A Beydoun², Alyssa A Gamaldo ${ }^{1}$, Alison Teel ${ }^{2}$, Alan B Zonderman ${ }^{1}$ and Youfa Wang ${ }^{3,4}$
}

\begin{abstract}
Background: Cognitive impairment, including dementia, is a major health concern with the increasing aging population. Preventive measures to delay cognitive decline are of utmost importance. Alzheimer's disease (AD) is the most frequent cause of dementia, increasing in prevalence from $<1 \%$ below the age of 60 years to $>40 \%$ above 85 years of age.

Methods: We systematically reviewed selected modifiable factors such as education, smoking, alcohol, physical activity, caffeine, antioxidants, homocysteine (Hcy), n-3 fatty acids that were studied in relation to various cognitive health outcomes, including incident AD. We searched MEDLINE for published literature (January 1990 through October 2012), including cross-sectional and cohort studies (sample sizes > 300). Analyses compared study finding consistency across factors, study designs and study-level characteristics. Selecting studies of incident AD, our meta-analysis estimated pooled risk ratios (RR), population attributable risk percent (PAR\%) and assessed publication bias.

Results: In total, 247 studies were retrieved for systematic review. Consistency analysis for each risk factor suggested positive findings ranging from $\sim 38.9 \%$ for caffeine to $~ 89 \%$ for physical activity. Education also had a significantly higher propensity for "a positive finding" compared to caffeine, smoking and antioxidant-related studies. Meta-analysis of 31 studies with incident $A D$ yielded pooled RR for low education ( $\mathrm{RR}=1.99 ; 95 \% \mathrm{Cl}: 1.30-3.04)$, high $\mathrm{Hcy}(\mathrm{RR}=1.93 ; 95 \% \mathrm{Cl}$ : 1.50-2.49), and current/ever smoking status ( $\mathrm{RR}=1.37$; $95 \% \mathrm{Cl}$ : 1.23-1.52) while indicating protective effects of higher physical activity and $n-3$ fatty acids. Estimated PAR\% were particularly high for physical activity (PAR\% $=31.9 ; 95 \% \mathrm{Cl}$ : 22.7-41.2) and smoking (PAR\%=31.09\%; 95\% Cl: 17.9-44.3). Overall, no significant publication bias was found.
\end{abstract}

Conclusions: Higher Hcy levels, lower educational attainment, and decreased physical activity were particularly strong predictors of incident AD. Further studies are needed to support other potential modifiable protective factors, such as caffeine.

Keywords: Cognition, Dementia, Alzheimer's disease, Risk factor, Nutrition, Meta-analysis

\section{Background}

Cognitive function refers to those mental processes that are crucial for the conduct of the activities of daily living. Such mental processes include attention, short-term and long-term memory, reasoning, coordination of movement and planning of tasks [1]. The prevalence of brain disorders affecting cognition (such as stroke and dementia) increases steadily in a linear fashion with age [2]. Cognitive

\footnotetext{
* Correspondence: baydounm@mail.nih.gov

'Laboratory of Epidemiology and Population Sciences, National Institute on Aging, NIA/NIH/IRP, 251 Bayview Blvd., Suite 100, Room \#: 04B118, Baltimore, MD 21224, USA

Full list of author information is available at the end of the article
}

impairment is a major health concern affecting loss of independence in daily activities in old age. Thus, special attention should be devoted to its prevention [3].

Dementia is relatively frequent in the elderly population and was shown to affect about $6.4 \%$ of European subjects over the age of 65 years [4]. A review of 50 original articles published between 1989 and 2002 using international data showed that prevalence of dementia for the very old group (85 years and over) varied from $16.7 \%$ in China [5] to $43 \%$ in Germany [6]. This variability was also reflected within separate age groups among the very old, ranging from $9.6 \%$ to $32 \%$ for the $85-89$ age category and from $41 \%$ to 
$58 \%$ for the 95+ age group. Incidence varied between 47 and 116.6 per 1000 and a separate meta-analytic study estimated the incidence in that age group (i.e. $85+$ ) to be around 104 per $1000[7,8]$.

Alzheimer's disease (AD) is the most frequent cause of dementia, increasing in prevalence from less than $1 \%$ below the age of 60 years to more than $40 \%$ above 85 years of age. The initial phase is generally marked by a progressive deterioration of episodic memory. Other impairments may be entirely absent in the beginning or consist of mild disturbances in naming and executive function. When the process advances, impairment spreads to other aspects of memory and other domains of cognition. Despite lack of curative treatment, epidemiological evidence reveals important risk factors for sporadic $A D$, many of which are non-modifiable (e.g. ApoE $\varepsilon 4$, age and sex). This highlights the importance for further evaluation of modifiable risk and preventive factors in that these potential factors may not only delay the onset of cognitive decline, but also can be easily treated. Aside from AD, less frequently occurring forms of dementia include vascular dementia ( $\mathrm{VaD})$, mixed dementia, dementia with Lewy bodies (DLB) and Parkinson's disease with dementia (PD-D), diagnostic criteria for which are described in Table 1. The relative prevalence of $\mathrm{AD}$ and $\mathrm{VaD}$ and the mixed version of both remain debatable. Ott and colleagues [9] estimated that for the very old, the prevalence of $\mathrm{AD}$ was $26.8 \%$ while that of $\mathrm{VaD}$ was $4.4 \%$. However, $\mathrm{VaD}$ appears to be more frequent than $\mathrm{AD}$ in certain Japanese and Chinese populations [10].

The present review focuses on selected modifiable risk and protective factors of cognitive impairment, cognitive decline and dementia (including AD), given that they are commonly studied and provide reliable and comparable data. In particular, we focused on the risk and protective factors that could be grouped under three broad categories, namely socioeconomic, behavioral, and nutritional. Consequently, other known risk factors that are modifiable but did not fall under these categories were excluded (e.g. obesity, type 2 diabetes, hypertension, depression, traumatic head injury etc.). In addition, the latter risk factors are potential mediating factors in the causal pathway between our selected factors and cognitive outcomes (e.g. obesity, depression, type 2 diabetes and hypertension may be on the causal pathway between physical activity and cognition; the same for diet $\rightarrow$ depression, obesity, type 2 diabetes, hypertension $\rightarrow$ cognition) and thus are more appropriately studied together rather than with their antecedent putative causes. This is the first study to systematically review those selected modifiable risk and protective factors for cognitive health outcomes in cross-sectional and cohort studies while comparing the consistency of association between those factors and across study-level characteristics. It is also among few recent studies to compare the strength of association across those factors in relation to incident $\mathrm{AD}$ using a similar approach $[19,20]$. Our findings could help guide future research and interventions.

\section{Methods}

Literature search

Using MEDLINE, we conducted a systematic review of the literature on cognitive function, decline and dementia focusing on specific risk factors. We considered both original research published between January 1990 and October 2012. We did not include titles prior to 1990 to ensure that diagnostic criteria for dementia and AD were comparable across studies. After an initial search using MESH keywords for risk factors (i.e. education, smoking, physical activity, caffeine/coffee/tea, alcohol, antioxidant/vitamin E, homocysteine and fatty acid) and a title containing the words (cognitive, dementia and Alzheimer), we assessed the retrieved papers for relevance by reading the titles and abstracts. Among those that were selected for review, information was retrieved including study design, contextual setting, sample size, main outcome and key findings.

Final inclusion criteria were: (1) Study sample size $>300$. Although this number is arbitrary, it was based on the fact that some study outcomes were relatively rare (e.g. incident AD: $<10 \%)$ and thus a smaller sample size for a cohort study for example might yield an underpowered study, depending on the distribution of the risk factor. (2) Study design is either cross-sectional or cohort study (thus case-control studies, review articles, commentaries, and basic science papers were excluded); (3) Outcomes include dementia, $\mathrm{AD}$, cognitive function, cognitive decline or cognitive impairment (including MCI)). Although all types of dementia were presented in our description of selected studies, focus was on the more prevalent sub-types including $\mathrm{AD}$ and $\mathrm{VaD}$ (4) Baseline sample includes general healthy population rather than special groups at risk (e.g. coronary heart disease patients). For the "cognitive decline" and "cognitive function" outcomes, we searched risk factors in the title to expand the range of studies selected beyond those based just on MESH keywords (i.e. "caffeine," "alcohol" and all other risk factors were also searched in titles when the outcome was "cognitive"). Both cohort and cross-sectional studies that were selected are presented in Table 2. The MEDLINE search and the studies excluded are laid out in Figure 1, showing main reasons for exclusion and final number of studies included for each risk factor. After inclusion of a study, we did not examine cross-references in order to ensure the comparability of the search strategy between risk factors.

Out of a total search of 6,837 titles and abstracts between 1990 and 2012 (range:126 for caffeine to 1,692 for education), 247 published original epidemiologic studies 
Table 1 Diagnostic criteria of Alzheimer's Disease (AD), Vascular Dementia (VaD), Mixed dementia (MD) and other dementias

\begin{tabular}{ll}
\hline Diagnosis & Criteria \\
\hline Alzheimer's disease (AD) & Development of multiple cognitive \\
(NINCDS-ADRDA) Source & deficits, with both memory impairment \\
and one (or more) of the following & cognitive disturbances: \\
& Aphasia (language disturbance) \\
& Apraxia (learned motor skills disturbance) \\
& Agnosia (visuospatial/sensory disturbance) \\
& Executive functioning (foresight, planning, \\
& insight anticipation) \\
& Significant impairment in social or \\
& Occupational functioning, representing \\
& a significant decline from a previous \\
& level of functioning \\
& Other diagnostic criteria: Hachinski \\
& Ischemic Score, ICD-10; DSM-IV; \\
& ADDTC; updated NINCDS-ADRDA
\end{tabular}

Vascular Dementia (VaD) (NINDS-AIREN) Source [13]

Vascular Dementia (VaD) (Modified Hachinski Ischemia Score: $\geq 4$ ) Source [14]:

Mixed Dementias (MDs)
Hachinski Ischemic score
ICD-10
DSM-IV

\section{ADDTC}

NINDS-AIREN
Cognitive decline from previous higher level of function in three areas of function including memory.

Evidence of cerebrovascular disease by examination

Evidence of cerebrovascular disease by neuroimaging

Onset either abrupt or within three months of a recognized stroke.

Two-point items

Abrupt onset

History of stroke

Focal neurologic symptoms

One-point items

Stepwise deterioration

Somatic complaints

History of hypertension

Emotional incontinence

Other diagnostic criteria: ICD-10; DSM-IV

Score based on clinical features: $\leq 4=\mathrm{AD} ; \geq 7=\mathrm{VaD}$; intermediate score of 5 or $6=\mathrm{MD}$.

Cases that met criteria for $\mathrm{VaD}$ and $\mathrm{AD}$

Cases with criteria for primary degenerative dementia of the Alzheimer type and clinical or neuroimagery feature of $\mathrm{VaD}$.

Presence of ischemic vascular disease and a second systemic or brain disorder.

Typical AD associated with clinical and radiological evidence of stroke.

Table 1 Diagnostic criteria of Alzheimer's Disease (AD), Vascular Dementia (VaD), Mixed dementia (MD) and other dementias (Continued)

Other Dementias

Fronto-Parietal Dementia

(FID) Source [15]:

Behavioral or cognitive deficits manifested by either (1) or (2)

(1) Early and progressive personality change, with problems in modulating behavior; inappropriate responses/ activities.

(2) Early and progressive language changes, with problems in language expression, word meaning, severe dysnomia.

Deficits represent a decline from baseline and cause significant impairment in social and occupational functioning.

Course characterized by gradual onset and continuing decline in function.

Other causes (eg, stroke, delirium) are excluded

Gradual onset and progressive cognitive decline

Dementia with Lewy Bodies (DLB) (Consensus Diagnosis for Dementia with Lewy Bodies) Source [16]:

Parkinson's Disease with Dementia (PD-D) Source [17]: Guidelines for the Clinical

Fluctuating in cognitive performance: Marked variation in cognition or function, or episodic confusion/decreased responsiveness.

Visual hallucinations: Usually well formed, unprovoked, benign.

Parkinsonism: Can be identical to Parkinson's Disease (PD), milder or symmetric.

Bradyphrenia (slowness of thought)

Executive impairment

Neuropsychiatric symptoms

Dysphonia

Sources [17,18]:.

Abbreviations: ADDTC: Alzheimer's Disease Diagnostic and Treatment Centers; DSM-IV: Diagnostic and Statistical Manual, $4^{\text {th }}$ edition; ICD-10: International Classification of Disease, $10^{\text {th }}$ edition; NINCDS-ADRDA: National Institute of Neurological and Communicative Disorders and Stroke - the Alzheimer's Disease and Related Disorders Association; NINDS-AIREN: National Institute of Neurological and Communicative Disorders and Stroke-Association Internationale pour la Recherche et l'Enseignement en Neurosciences; PD-D: Parkinson's disease with dementia.

(167 cohort-, 80 cross-sectional studies) were included in our review. A database was built accordingly using Endnote ver. X3 [259]. Each study was summarized in Table 2 by listing the sample characteristics (age, gender, country), study design, sample size and type of outcome. Given the diversity of types of outcomes, a quantitative meta-analysis for all studies with all outcomes was not possible. Thus, a qualitative method to assess overall consistency was 
Table 2 Summary of epidemiologic studies of risk and protective factors for cognitive outcomes included in the review

\begin{tabular}{|c|c|c|c|c|c|c|c|}
\hline Study & Age/gender & Year & Country & Study design & Sample size & Outcomes & Findings \\
\hline (1) Education & \multicolumn{7}{|c|}{ Hypothesis: Lower education is associated with lower cognitive function or higher rate of cognitive decline or increased risk of dementia(including AD) } \\
\hline [21] & $65+/ B$ & 1990 & China & Cross-sectional & $N=5,055$ & Prevalent AD and dementia & + \\
\hline [22] & Mean:58.5/B & 1991 & Nigeria & Cross-sectional & $N=1,350$ & Cognitive function & + \\
\hline [23] & $65+/ B$ & 1992 & France & Cross-sectional & $N=2,792$ & Cognitive function & + \\
\hline [24] & $68-77 / B$ & 1992 & Finland & Cross-sectional & $N=403$ & Cognitive function & + \\
\hline [25] & $65+/ B$ & 1993 & US & Cohort & $N=4,485$ & Cognitive decline & + \\
\hline [26] & $75+/ B$ & 1994 & England & Cohort & $N=1,195$ & Indicent dementia & 0 \\
\hline [27] & $65+/ B$ & 1994 & US & Cohort & $N=10,294$ & Incident cognitive impairment & + \\
\hline [28] & $55+/ B$ & 1995 & US & Cohort & $N=3,330$ & Incident $A D$ and $\mathrm{VaD}$ & $+(\mathrm{VaD})$ \\
\hline [29] & $18+/ B$ & 1995 & US & Cohort & $N=14,883$ & Indicent dementia & + \\
\hline [9] & $55-106 / \mathrm{B}$ & 1995 & The Netherlands & Cross-sectional & $N=7,528$ & Prevalent dementia, AD and VaD & + \\
\hline [30] & $65+/ B$ & 1996 & US & Cross-sectional & $N=2,212$ & $\begin{array}{l}\text { Prevalent dementia and cognitive } \\
\text { impairment }\end{array}$ & + \\
\hline [31] & $68-78 / B$ & 1996 & Finland & Cross-sectional & $N=403$ & Cognitive decline & + \\
\hline [32] & $70+/ B$ & 1997 & Australia & Cohort & $N=652$ & Cognitive decline & + \\
\hline [33] & $65+/ B$ & 1997 & US & Cohort & $N=642$ & Incident AD & + \\
\hline [34] & $50-80 / \mathrm{B}$ & 1997 & Austria & Cross-sectional & $N=1,927$ & Cognitive function & + \\
\hline [35] & Mean:75/M & 1997 & The Netherlands & Cohort & $N=528$ & Cognitive decline & + \\
\hline [36] & 69-74/M & 1997 & Sweden & Cross-sectional & $N=504$ & Cognitive function & + \\
\hline [37] & $55-84 / B$ & 1997 & The Netherlands & Cohort & $N=5,825$ & $\begin{array}{l}\text { Cognitive function, decline and } \\
\text { incident/prevalent dementia }\end{array}$ & + \\
\hline [38] & $65-84 / B$ & 1997 & The Netherlands & Cohort & $N=2,063$ & Incident dementia & +(IQ better predcitor) \\
\hline [39] & $47-68 / B$ & 1998 & US & Cross-sectional & $N=14,000$ & Cognitive function & + \\
\hline [40] & $60+/ B$ & 1998 & Italy & Cross-sectional & $N=495$ & Prevalent dementia & 0 \\
\hline [41] & $65+/ B$ & 1998 & Taiwan & Cross-sectional & $N=2,915$ & Prevalent dementia, AD and VaD & $+(\mathrm{AD})$ \\
\hline [42] & $18+/ B$ & 1999 & US & Cohort & $N=1,488$ & Cognitive decline & + \\
\hline [43] & $65+/ B$ & 1999 & France & Cohort & $N=3,675$ & Incident AD & + \\
\hline [44] & $55-106 / \mathrm{B}$ & 1999 & The Netherlands & Cohort & $N=6,827$ & Incident dementia & + (women) \\
\hline [45] & $85+/ B$ & 2000 & Sweden & Cohort & $N=494$ & Cognitive decline and function & + \\
\hline [46] & $75+/ B$ & 2001 & Sweden & Cohort & $N=1,296$ & Incident dementia and AD & + \\
\hline [47] & $65+/ B$ & 2002 & Spain & Cohort & $N=557$ & Cognitive decline & + \\
\hline [48] & $70+/ B$ & 2002 & US & Cross-sectional & $N=6,577$ & Cognitive function & + \\
\hline [49] & $65+/ B$ & 2002 & Brazil & Cross-sectional & $N=1,656$ & Prevalent dementia and $A D$ & + \\
\hline
\end{tabular}


Table 2 Summary of epidemiologic studies of risk and protective factors for cognitive outcomes included in the review (Continued)

\begin{tabular}{|c|c|c|c|c|c|c|c|}
\hline [50] & $65+/ B$ & 2002 & Italy & Cross-sectional & $N=1,016$ & Prevalent $\mathrm{AD}$ and $\mathrm{VaD}$ & + \\
\hline [51] & $45-59 / M$ & 2002 & US & Cross-sectional & $N=1,839$ & Cognitive function & + \\
\hline [52] & 70-79/W & 2003 & US & Cohort & $N=19,319$ & Cognitive function and decline & + \\
\hline [53] & 70-79/B & 2005 & US & Cohort & $N=4,030$ & Cognitive decline & $+($ ApoE- $)$ \\
\hline [54] & $66+/ W$ & 2006 & US & Cohort & $N=6,314$ & Cognitive function and decline & + \\
\hline [55] & $\begin{array}{l}\text { Mean age: } \\
\sim 75 / \mathrm{B}\end{array}$ & 2006 & US & Cohort & $N=2,786$ & Incident dementia & +(both whites and blacks) \\
\hline [56] & $55+/ B$ & 2006 & China & Cross-sectional & $N=34,807$ & Prevalent $\mathrm{AD}$ and $\mathrm{VaD}$ & $+(A D)$ \\
\hline [57] & $50+/ B$ & 2006 & China & Cross-sectional & $N=16,095$ & Prevalent dementia and $\mathrm{AD}$ & + \\
\hline [58] & $65+/ B$ & 2007 & Guam & Cross-sectional & $N=2,789$ & Prevalent dementia and $\mathrm{AD}$ & + \\
\hline [59] & $64-81 / \mathrm{B}$ & 2007 & The Netherlands & Cross-sectional & $N=578$ & Cognitive function & + \\
\hline [60] & $60-64 / B$ & 2009 & Australia & Cohort & $N=416$ & Cognitive decline & 0 \\
\hline [61] & $30-64 / B$ & 2009 & US & Cross-sectional & $N=1,345$ & Cognitive function & +(literacy better predictor) \\
\hline [62] & $65-96 / B$ & 2009 & Spain & Cross-sectional & $N=1,074$ & Prevalent dementia & + \\
\hline [63] & $80+/ B$ & 2009 & UK & Cohort & $N=3,336$ & Incident dementia & + \\
\hline [64] & Mean:72/B & 2009 & US & Cohort & $N=6,000$ & Cognitive function and decline & $\begin{array}{l}\text { +(cognitive function) O(cognitive } \\
\text { decline) }\end{array}$ \\
\hline [65] & $60+/ B$ & 2010 & Malaysa & Cross-sectional & $N=2,980$ & Prevalent dementia & + \\
\hline [66] & $55+/ B$ & 2010 & India & Cross-sectional & $N=2,466$ & Prevalent dementia and $\mathrm{AD}$ & + \\
\hline [67] & $65+/ B$ & 2010 & Brazil & Cross-sectional & $N=2,003$ & Cognitive function & + \\
\hline [68] & $60+/ B$ & 2011 & Brazil & Cohort & $N=1,461$ & Cognitive decline & - \\
\hline [69] & $60-98 / B$ & 2011 & Italy & Cohort & $N=1,270$ & Incident cognitive impairment & + \\
\hline [70] & $60+/ B$ & 2011 & Mexico & Cohort & $N=7,000$ & Prevalent and incident dementia & + \\
\hline [71] & $54-95 / B$ & 2011 & US & Cohort & $N=1,014$ & Cognitive decline & 0 \\
\hline Study & Age/gender & Year & Country & Design & Sample size & Outcome & Finding \\
\hline \multicolumn{8}{|l|}{ (2) Behavioral } \\
\hline (2.1.) Smoking & \multicolumn{7}{|c|}{ Hypothesis: Current or ever smoking status is associated with lower cognitive function or higher rate of cognitive decline or increased risk of dementia(including AD) } \\
\hline [72] & $65+/ B$ & 1993 & US & Cohort & $N=1,201$ & Cognitive decline & 0 \\
\hline [73] & $65+/ B$ & 1994 & France & Cross-sectional & $N=3,770$ & Prevalent $A D$, cognitive impairment & 0 \\
\hline [74] & $74+/ B$ & 1996 & US & Cohort & $N=647$ & Cognitive function & 0 \\
\hline$[75]$ & Mean:58.6/M & 1997 & US & Cohort & $N=3,429$ & Cognitive impairment & + \\
\hline [36] & $69-74 / M$ & 1997 & Sweden & cross-sectional & $N=504$ & Cognitive function & + \\
\hline [76] & $75+/ B$ & 1998 & Australia & Cohort & $N=327$ & Incident dementia and $\mathrm{AD}$ & 0 \\
\hline
\end{tabular}


Table 2 Summary of epidemiologic studies of risk and protective factors for cognitive outcomes included in the review (Continued)

\begin{tabular}{|c|c|c|c|c|c|c|c|}
\hline [77] & adults/B & 1998 & US & Cohort & $N=1,469$ & Cognitive function & 0 \\
\hline [78] & $55+/ B$ & 1998 & US & Cohort & $N=6,870$ & Incident dementia and AD & $+\left(\mathrm{ApoE}^{-}\right)$ \\
\hline [79] & $56-69 / M$ & 1999 & US & Cross-sectional & $N=569$ & Cognitive impairment & $+\left(\mathrm{ApoE} 4^{-}\right)$ \\
\hline$[80]$ & $45-59 / M$ & 1999 & UK & Cross-sectional & $N=1,870$ & Cognitive function & 0 \\
\hline [81] & $65+/ B$ & 2000 & UK & Cohort & $N=889$ & Cognitive Impairment & + \\
\hline [82] & Mean: 81/M & 2000 & UK & Cohort & $N=34,439$ & Definite or probable AD & 0 \\
\hline [83] & $45-70 / B$ & 2002 & Netherlands & Cohort & $N=1,927$ & Cognitive change & + \\
\hline [84] & $65+/ B$ & 2003 & Taiwan & Cohort & $N=798$ & Cognitive decline & 0 \\
\hline$[85]$ & 43-53/B & 2003 & UK & Cohort & $N=3,035$ & Cognitive decline & + \\
\hline [86] & Mean:78/M & 2003 & US & Cohort & $N=3,734$ & Incident AD & + \\
\hline [87] & $60+/ B$ & 2003 & China & Cross-sectional & $N=3,012$ & Cognitive impairment & + \\
\hline [88] & $60+/ B$ & 2004 & China & Cohort & $N=2,820$ & Incident dementia and AD & + \\
\hline [89] & $65+/ B$ & 2004 & European cohorts & Cohort & $N=17,610$ & Cognitive decline & + \\
\hline [90] & $65-84 / B$ & 2004 & Italy & Cohort & $N=5,632$ & Mild cognitive impairment & 0 \\
\hline [91] & $40-80 / M$ & 2004 & The Netherlands & Cross-sectional & $N=900$ & Cognitive function & 0 \\
\hline [92] & Mean:75/B & 2005 & US & Cohort & $N=791$ & Cognitive function and decline & $+\left(75+\right.$ and $\left.A p o E 4^{-}\right)$ \\
\hline [93] & $40-44 / B$ & 2005 & US & Cohort & $N=8,845$ & Incident dementia & + \\
\hline [94] & $50+/ B$ & 2006 & UK & Cohort & $N=2,000$ & Cognitive function & + \\
\hline [95] & $55+/ B$ & 2007 & The Netherlands & Cohort & $N=6,868$ & Incident dementia and $\mathrm{AD}$ & + \\
\hline [96] & $43-70 / B$ & 2008 & The Netherlands & Cohort & $N=1,964$ & Cognitive decline & + \\
\hline [97] & $35-55 / B$ & 2008 & France & Cohort & $N=4,659$ & Cognitive function & + (memory) \\
\hline [98] & $46-70 / B$ & 2009 & US & Cohort & $N=11,151$ & Incident dementia & + \\
\hline [99] & $65+/ B$ & 2009 & US & Cohort & $N=1,557$ & Cognitive decline & + \\
\hline [100] & $90-108 / \mathrm{B}$ & 2009 & China & Cross-sectional & $N=681$ & Cognitive impairment & $+($ men) \\
\hline [63] & Mean:83.5/B & 2009 & UK & Cohort & $N=3,336$ & Incident dementia & 0 \\
\hline [101] & $65-79 / B$ & 2010 & Finland & Cohort & $N=1,449$ & Incident dementia and AD & + \\
\hline [102] & Mean:71.8/B & 2010 & Taiwan & Cohort & $N=1,436$ & Incident cognitive impairment & - \\
\hline [103] & $50 y / M$ & 2011 & Sweden & Cohort & $N=2,268$ & Incident dementia and AD & $+($ non-AD) \\
\hline [104] & Mean:60.1/B & 2011 & Finland & Cohort & $N=21,123$ & Incident dementia and AD & + \\
\hline [105] & $44-69 / B$ & 2012 & UK & Cohort & $N=7,236$ & Cognitive decline & $+($ men) \\
\hline
\end{tabular}


Table 2 Summary of epidemiologic studies of risk and protective factors for cognitive outcomes included in the review (Continued)

\begin{tabular}{|c|c|c|c|c|c|c|c|}
\hline Study & Age/gender & Year & Country & Design & Sample size & Outcome & Finding \\
\hline (2.2.) Alcohol & \multicolumn{7}{|c|}{ Hypothesis: Moderate alcohol consumption is protective against poorer cognitive function, higher rate of cognitive decline and dementia } \\
\hline [106] & $65+/ B$ & 1996 & US & Cross-sectional & $N=2,040$ & Cognitive function & $+(J$-shaped $)$ \\
\hline [107] & $59-71 / B$ & 1997 & France & Cross-sectional & $N=1,389$ & Cognitive function & + (women) \\
\hline$[76]$ & $75+/ B$ & 1998 & Australia & Cohort & $N=327$ & Incident dementia and AD & 0 \\
\hline [77] & $40-80 / B$ & 1998 & US & Cohort & $N=1469$ & Cognitive function & 0 \\
\hline [108] & $55-88 / B$ & 1999 & USA & Cohort & $N=1786$ & Cognitive function & $+($ U-shaped $)$ \\
\hline [109] & $65+/ B$ & 2001 & US & Cross-sectional & $N=1,836$ & Cognitive function & $\begin{array}{l}+(U \text {-shaped for men, linear for } \\
\text { women })\end{array}$ \\
\hline [110] & Mean:70/B & 2001 & Italy & Cross-sectional & $N=15,807$ & Cognitive impairment & $+($ U-shaped $)$ \\
\hline [83] & $45-70 / B$ & 2002 & Netherlands & Cohort & $N=1,927$ & Cognitive change & $+($ women $>$ men $)(\mathrm{J}$-shaped $)$ \\
\hline [111] & $18+/ B$ & 2000 & US & Cohort & $N=1,448$ & Cognitive decline & +(women > men) (U-shaped) \\
\hline [112] & $53 / \mathrm{B}$ & 2003 & US & Cross-sectional & $N=10,317$ & Cognitive function & 0 \\
\hline [87] & $60+/ B$ & 2003 & China & Cohort & $N=3,012$ & Cognitive impairment & - \\
\hline [113] & $65-79 / B$ & 2004 & Finland & Cohort & $N=1,464$ & Cognitive function & $+\left(\right.$ U-shaped) $-\left(\right.$ ApoE4 $\left.^{+}\right)$ \\
\hline [114] & $65+/ B$ & 2004 & US & Cohort & $N=4,417$ & Cognitive function & $\begin{array}{l}\text { +(current drinker vs. former or } \\
\text { abstainer) }\end{array}$ \\
\hline [115] & $35-55 / B$ & 2004 & UK & Cohort & $N=10,308$ & Cognitive function & $\begin{array}{l}+(\text { linear, some cognitive } \\
\text { domains) }\end{array}$ \\
\hline [116] & $65+/ B$ & 2005 & US & cohort & $N=1,624$ & Cognitive function & $\begin{array}{l}\text { +(current drinker vs. former or } \\
\text { abstainer) }\end{array}$ \\
\hline [117] & Mean:74/B & 2005 & US & Cohort & $N=1,098$ & Cognitive function and decline & $+(J$-shaped $)$ \\
\hline [118] & $43-53 / B$ & 2005 & UK & Cohort & $N=1,764$ & Cognitive decline & $\begin{array}{l}\text { Linear + (slower memory } \\
\text { decline: men) -(faster } \\
\text { psychomotor speed } \\
\text { decline: women) }\end{array}$ \\
\hline [119] & $\begin{array}{l}20-24,40-44 \\
60-64 / B\end{array}$ & & Australia & Cross-sectional & $N=7,485$ & Cognitive function & $\begin{array}{l}\text { J-shaped + (light drinkers } \\
\text { vs. abstainers) }\end{array}$ \\
\hline [120] & 70-81/W & 2005 & US & Cohort & $N=11,102$ & Cognitive function and decline & $\begin{array}{l}+(J \text {-shaped) (cognitive } \\
\text { decline) }\end{array}$ \\
\hline [121] & $65-89 / \mathrm{M}$ & 2006 & US & Cross-sectional & $N=760$ & Cognitive function & $+($ linear, J-shaped) \\
\hline [122] & $40+/ B$ & 2006 & US & Cohort & $N=1,428$ & Cognitive decline & +(linear) \\
\hline [123] & $65-79 / B$ & 2006 & Finland & Cross-sectional & $N=1,341$ & Cognitive function & +(linear) \\
\hline [124] & $65-84 / B$ & 2007 & US & Cohort & $N=1,445$ & Incident $\mathrm{MCl}$ and $\mathrm{MCl} \rightarrow$ dementia & $+($ U-shaped $)$ \\
\hline$[125]$ & $50+/ B$ & 2010 & China & Cohort & $N=30,499$ & $\mathrm{MCl} \rightarrow$ dementia & $+(J$-shaped $)$ \\
\hline$[126]$ & $50+/ B$ & 2010 & China & Cross-sectional & $N=9,571-28,537$ & Cognitive function & $\begin{array}{l}\text { +(occasional alcohol use vs. } \\
\text { none) }\end{array}$ \\
\hline
\end{tabular}


Table 2 Summary of epidemiologic studies of risk and protective factors for cognitive outcomes included in the review (Continued)

\begin{tabular}{|c|c|c|c|c|c|}
\hline [127] & $65+/ B$ & 2009 & China & Cross-sectional & $N=314$ \\
\hline [128] & $70 / \mathrm{B}$ & 2011 & UK & Cross-sectional & $N=922$ \\
\hline [129] & $55+/ B$ & 2011 & US & Cohort & $N=1,337$ \\
\hline [130] & $55+/ B$ & 2011 & France & Cross-sectional & $N=4,073$ \\
\hline [131] & $45+/ B$ & 2012 & US & Cohort & $N=571$ \\
\hline Study & Age/gender & Year & Country & Design & Sample siz \\
\hline $\begin{array}{l}\text { (2.3.) Physical } \\
\text { activity }\end{array}$ & \multicolumn{5}{|c|}{ Hypothesis: Physical activity is protective against poorer cognitive function, high } \\
\hline [132] & $70+/ B$ & 2001 & Hong Kong & Cohort & $N=2030$ \\
\hline [133] & $65+/ B$ & 2001 & Canada & Cohort & $N=4615$ \\
\hline [134] & $65-84 / M$ & 2001 & Netherlands & Cohort & $N=347$ \\
\hline [135] & $65+/ F$ & 2001 & US & Cohort & $N=5,925$ \\
\hline [136] & $75+/ B$ & 2003 & US & Cohort & $N=469$ \\
\hline [137] & 71-93/M & 2004 & US & Cohort & $N=2257$ \\
\hline [138] & $65+/ B$ & 2004 & US & Cohort & $N=1146$ \\
\hline [139] & $80+/ M$ & 2004 & European countries & Cohort & $N=295$ \\
\hline [140] & 70-81/W & 2004 & US & Cohort & $N=18766$ \\
\hline [141] & $65+/ M$ & 2005 & US & Cohort & $N=3375$ \\
\hline [142] & $65-79 / \mathrm{B}$ & 2005 & Sweden & Cohort & $N=1449$ \\
\hline [143] & $65+/ B$ & 2005 & US & Cohort & $N=4055$ \\
\hline [144] & $75+/ B$ & 2006 & Sweden & Cohort & $N=776$ \\
\hline [145] & $65+/ B$ & 2006 & US & Cohort & $N=1740$ \\
\hline [146] & $65+/ W$ & 2010 & US & Cross-sectional & $N=9344$ \\
\hline [147] & $60+/ B$ & 2008 & Greece & Cohort & $N=732$ \\
\hline [148] & $71-92 / M$ & 2008 & US & Cohort & $N=2263$ \\
\hline [149] & $70+/ B$ & 2009 & Italy & Cross-sectional & $N=668$ \\
\hline [100] & $90-108 / \mathrm{B}$ & 2009 & China & Cross-sectional & $N=681$ \\
\hline [150] & $65+/ B$ & 2009 & US & Cohort & $N=1880$ \\
\hline [151] & 70-79/B & 2009 & US & Cohort & $N=2509$ \\
\hline [152] & Mean:51y/B & 2010 & Iceland & Cohort & $N=4945$ \\
\hline [153] & $55+/ B$ & 2010 & Germany & Cohort & $N=3903$ \\
\hline [154] & $60+/ B$ & 2010 & US & Cohort & $N=5903$ \\
\hline
\end{tabular}

Cognitive impairment
Cognitive function
Cognitive function
Cognitive function
Cognitive decline
Outcome

$+($ (U-shaped)

+(linear, verbal memory)

0 -(executive function)

-(high alcohol use, Low SES)

+ (heavy drinking)

Finding

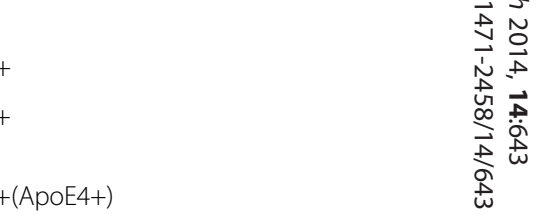

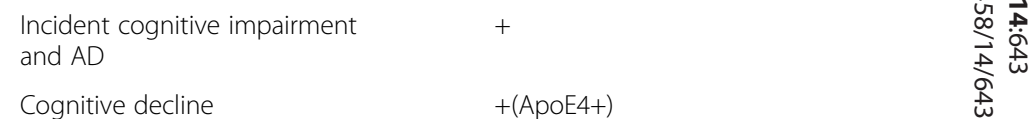

Cognitive decline

Incident dementias (AD, VaD and others)

Incident dementia and AD

Cognitive decline

Cognitive decline

Cognitive decline

Incident dementia and $\mathrm{AD}$

Incident dementia and AD

$+$

$+$

$+$

$+$

$+($ ApoE4-)

Cognitive decline

Incident dementia

Incident dementia and AD

Cognitive impairment

Cognitive impairment

Dementia

Cognitive decline

Cognitive impairment

Incident AD

Cognitive function and decline

Cognitive function and dementia

Incident cognitive impairment 
Table 2 Summary of epidemiologic studies of risk and protective factors for cognitive outcomes included in the review (Continued)

\begin{tabular}{|c|c|c|c|c|c|c|c|}
\hline [155] & $65+/ W$ & 2010 & US & Cross-sectional & $N=9344$ & Cognitive function and impairment & + \\
\hline [156] & Mean:82/B & 2012 & US & Cohort & $N=716$ & AD Cognitive decline & + \\
\hline [157] & $40-84 / B$ & 2012 & US & Cohort & $\begin{array}{l}N=405 \text { (40-59 years) } N=342(60-84 \\
\text { years) }\end{array}$ & Cognitive function & + \\
\hline [158] & $65+/ B$ & 2012 & US & Cohort & $N=2491$ & Incident dementia \& AD & + \\
\hline Study & Age/gender & Year & Country & Design & Sample size & Outcome & Finding \\
\hline \multicolumn{8}{|l|}{ (3) Nutritional } \\
\hline \multicolumn{8}{|c|}{$\begin{array}{l}\text { (3.1) Caffeine(coffee Hypothesis: Caffeine consumption is protective against poorer cognitive function, higher rate of cognitive decline and dementia } \\
\text { or tea) }\end{array}$} \\
\hline [159] & $18+/ B$ & 1993 & UK & Cross-sectional & $N=9,003$ & Cognitive function & +(caffeine) \\
\hline [160] & Mean: 73/B & 2002 & US & Cross-sectional & $N=1,528$ & Cognitive function & O(coffee) \\
\hline [161] & 24-81/B & 2003 & The Netherlands & Cohort & $N=1,376$ & Cognitive change & O(caffeine) \\
\hline [162] & $70+/ B$ & 2006 & Japan & Cross-sectional & $N=1,003$ & Cognitive impairment & + (green tea) \\
\hline [163] & Mean 75/M & 2007 & $\begin{array}{l}\text { Finland, the Netherlands } \\
\text { and Italy }\end{array}$ & Cohort & $N=667$ & Cognitive decline & +(coffee, J-shaped) \\
\hline [164] & $55+/ B$ & 2008 & Singapore & Cohort & $N=1,438$ & Cognitive impairment and decline & + (tea) \\
\hline [165] & $65-79 / B$ & 2009 & Finland & Cohort & $N=1,409$ & Incident dementia and AD & +(coffee), O(tea) \\
\hline [100] & $90+/ B$ & 2009 & China & Cross-sectional & $N=681$ & Cognitive impairment & +(tea, men) \\
\hline [166] & $65+/ B$ & 2009 & Finland & Cohort & $N=2,606$ & $\begin{array}{l}\text { Cognitive function, incident } \\
\text { dementia and } \mathrm{MCl}\end{array}$ & O(coffee) \\
\hline [167] & $70-74 / B$ & 2009 & Norway & Cross-sectiona & $N=2,031$ & Cognitive impairment & + (tea) \\
\hline [168] & $17-92 / B$ & 2009 & UK & Cross-sectional & $N=3,223$ & Cognitive function & O(caffeine) \\
\hline [169] & $70 / \mathrm{B}$ & 2010 & UK & Cohort & $N=923$ & Cognitive function & $+($ coffee $) ;-$ (tea) \\
\hline [170] & $55+/ B$ & 2010 & Singapore & Cross-sectional & $N=716$ & Cognitive function & + (tea) \\
\hline [171] & $65+/ B$ & 2010 & France & Cohort & $N=641$ & Cognitive decline & +(caffeine, women) \\
\hline [172] & $65+/ B$ & 2010 & Portugal & Cohort & $N=648$ & Cognitive decline & +(caffeine, women) \\
\hline [173] & $65+/ B$ & 2011 & US & Cohort & $N=4,809$ & Cognitive decline & +(caffeine, women) \\
\hline [174] & Mean:54/M & 2011 & US & Cohort & $N=3,494$ & $\begin{array}{l}\text { Incident dementia and cognitive } \\
\text { impairment }\end{array}$ & O(caffeine) \\
\hline [175] & Mean:91.4/B & 2012 & Singapore & Cohort & $N=7,139$ & Cognitive change & + (tea) \\
\hline Study & Age/gender & Year & Country & Design & Sample size & Outcome & Finding \\
\hline $\begin{array}{l}\text { (3.2) Antioxidants/ } \\
\text { Vitamin E }\end{array}$ & \multicolumn{7}{|c|}{ Hypothesis: Antioxidants, including vitamin E, are protective against poorer cognitive function, higher rate of cognitive decline and dementia(including AD) } \\
\hline [176] & $55-95 / B$ & 1996 & Netherlands & cohort & $N=5,182$ & Cognitive function & + \\
\hline [177] & $66-97 / B$ & 1998 & US & Cohort & $N=1,059$ & Cognitive function & 0 \\
\hline
\end{tabular}


Table 2 Summary of epidemiologic studies of risk and protective factors for cognitive outcomes included in the review (Continued)




Table 2 Summary of epidemiologic studies of risk and protective factors for cognitive outcomes included in the review (Continued)

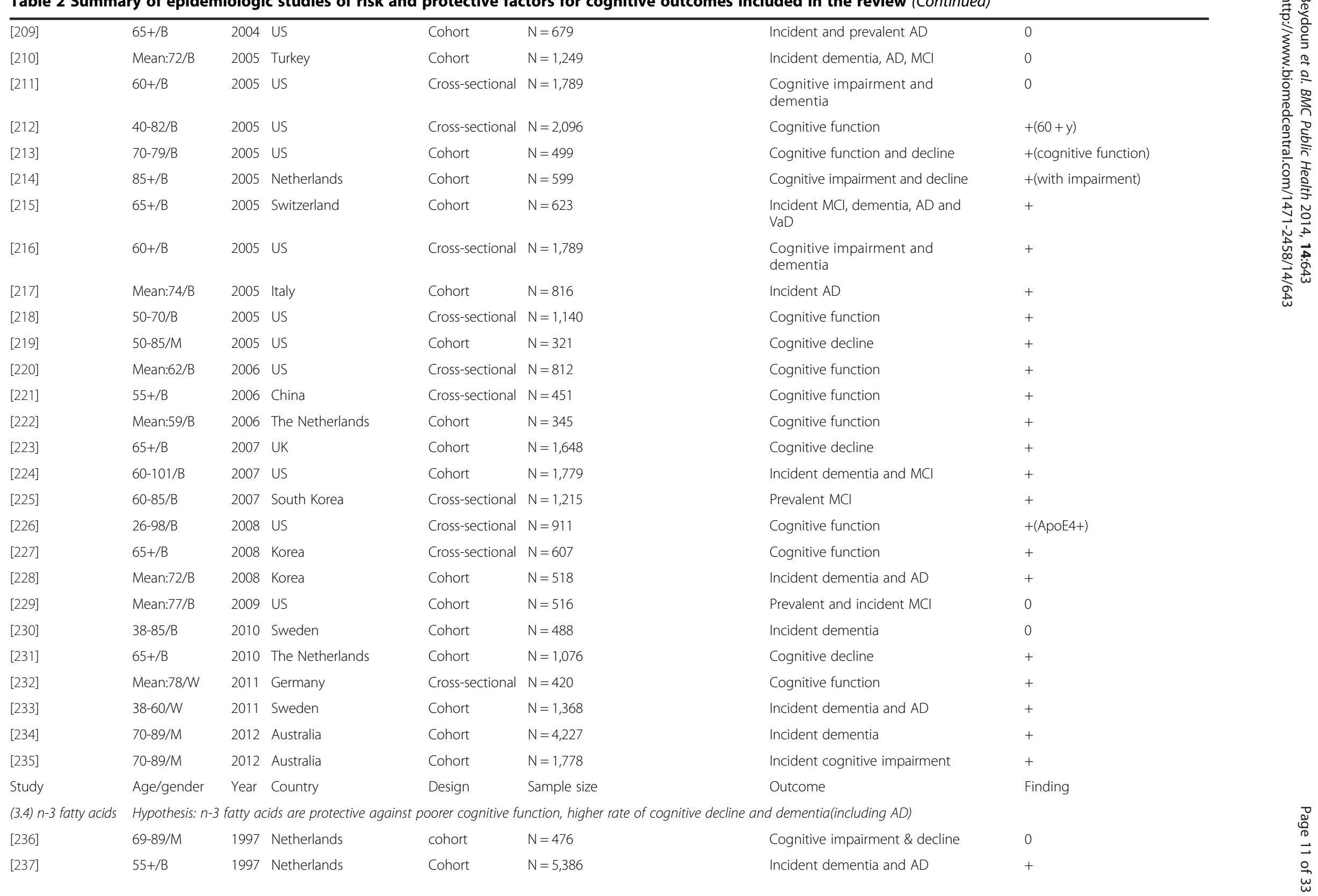


Table 2 Summary of epidemiologic studies of risk and protective factors for cognitive outcomes included in the review (Continued)

\begin{tabular}{|c|c|c|c|c|c|c|c|}
\hline [238] & $55+/ B$ & 2002 & Netherlands & Cohort & $N=5,395$ & Incident dementia and AD & 0 \\
\hline [239] & $65-94 / B$ & 2003 & US & Cohort & $N=815$ & Incident AD & + \\
\hline [240] & $45-70 / B$ & 2004 & Netherlands & Cross-sectional & $N=1,613$ & Cognitive function & + \\
\hline [241] & $65+/ B$ & 2005 & US & Cohort & $N=3,718$ & Cognitive decline & 0 \\
\hline [242] & $65+/ B$ & 2007 & France & Cohort & $N=8,085$ & Incident dementia and $A D$ & $+($ ApoE4-) \\
\hline [243] & $50+/ B$ & 2007 & US & Cohort & $N=2,251$ & Cognitive decline & +(hypertensive, Dyslipidemic) \\
\hline [244] & Mean:76/B & 2007 & Italy & Cross-sectional & $N=935$ & Prevalent dementia & + \\
\hline [245] & $50-70 / B$ & 2007 & Netherlands & Cohort & $N=404-807$ & Cognitive function and change & +(change) \\
\hline [246] & $50+/ B$ & 2008 & US & Cohort & $N=2,251-7,814$ & Cognitive decline & +(hypertensives) \\
\hline [247] & $65-80 / \mathrm{B}$ & 2008 & Finland & Cohort & $N=1,449$ & $\mathrm{MCl}$ and cognitive function & + \\
\hline [248] & Mean:78/B & 2008 & France & Cohort & $N=1,214$ & Incident dementia & + \\
\hline [249] & $65+/ B$ & 2009 & Multi-national & Cross-sectional & $N=14,960$ & Prevalent dementia & + \\
\hline [250] & $55+/ B$ & 2009 & Netherlands & Cohort & $N=5,395$ & Incident dementia and $\mathrm{AD}$ & 0 \\
\hline [251] & $65+/ B$ & 2009 & Canada & Cohort & $N=663$ & Incident dementia or AD & 0 \\
\hline [252] & Mean:68/M & 2009 & Netherlands & Cohort & $N=1,025$ & Cognitive function & 0 \\
\hline [253] & $76-82 / \mathrm{W}$ & 2009 & France & Cohort & $N=4,809$ & Cognitive decline & + \\
\hline [254] & Mean:75/B & 2010 & Spain & Cross-sectional & $N=304$ & Cognitive impairment & + \\
\hline [255] & $35-54 / B$ & 2010 & US & Cross-sectional & $N=280$ & Cognitive function & + \\
\hline [256] & $55+/ B$ & 2011 & Singapore & Cohort & $N=1,475$ & Cognitive function and decline & +(supplements) \\
\hline [257] & Mean: 64/B & 2011 & France & Cohort & $N=3,294$ & Cognitive impairment & + \\
\hline [258] & $65+/ B$ & 2011 & France & Cohort & $N=1,228$ & Cognitive decline & $+\left(\right.$ ApoE $^{+} ;$depressed $)$ \\
\hline
\end{tabular}

Hypothesized association; - Association against hypothesis; O: No association.
Abbreviations: AD: Alzheimer's Disease; ApoE: Apolipoprotein E; B: Both; M: Men; MCI: Mild Cognitive Impairment; MD = Mixed Dementia; OD = Other dementia; UK: United Kingdom; US: United States; VaD: Vascular Abbreviations: AD: Alzh 


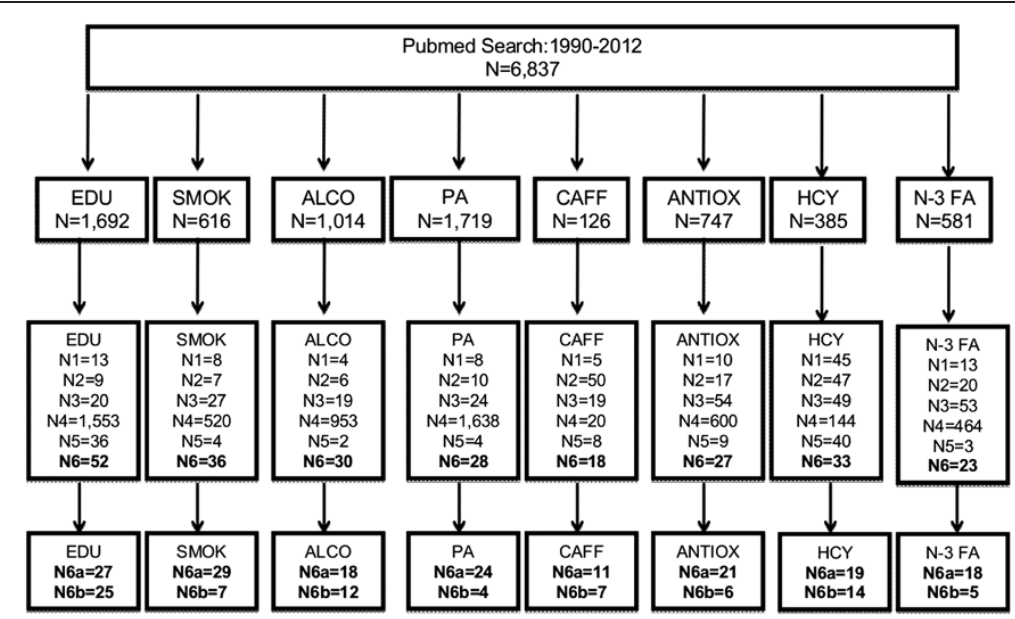

Figure 1 Flowchart of study selection for systematic review and meta-analysis. Notes: MEDLINE searches (1990-2012) included the following: (1) "Risk factor" as MESH term AND "Dementia" in title; (2) "Risk factor" as MESH term AND "Alzheimer" in title; (3) "Risk factor" as MESH term AND "Alzheimer" in title; (4) "Risk factor" as MESH term AND "cognitive" in title; (5) "Risk factor" in title and "cognitive" in title. Given that each search is not mutually exclusive of other searches, there were duplicates which were deleted from the final number of included studies. The following notations are defined follows: N1 = Studies excluded from all searches combined due to small sample size; N2 = Studies excluded from all searches combined due to design being neither cross-sectional nor cohort; N3 = Studies excluded from all searches combined due to being a review or a letter to the editor; N4 = Studies excluded from all searches combined due to lack of relevance to topic or hypothesis; N5 = Studies excluded from all searches combined for other reasons (e.g. special group of people); N6= Final included studies; N6a = Final included cohort studies; N6b = Final included cross-sectional studies.

conducted. This analysis was mainly based on the hypothesized direction of association and the final conclusion of the study. Thus, main findings based on the pre-set hypothesis was coded (+: supports the hypothesis; 0: no significant finding; -: against the hypothesis). In addition, within + , we coded studies as partially supporting the hypothesis for three main reasons: "some outcomes but not others", "some exposures but not others", "some sub-group(s) but not others". These papers are sorted by risk factor, year of publication and first author's last name.

\section{Descriptive analysis}

In the descriptive part of the analysis, a data point consisted of a study finding within a design/risk factor dyad (e.g. cohort/education). Using the data points, we conducted an analysis to assess consistency of positive findings across risk factors and study designs (cohort vs. cross-sectional). In particular, we estimated the \% of positive findings for all participants and most outcomes; \% of positive findings for some outcomes or exposures but not others; \% of positive findings for sub-groups; \% null findings; \% of findings against hypothesized direction. In addition, study-level characteristics (e.g. year and country of publication, study design, type of cognitive outcome, sample size, age group, sex) were described in detail and compared across risk factors, using $X^{2}$ test, independent samples $t$-test and one-way ANOVA.

\section{Consistency analysis: all data points}

In this part of the analysis, we modeled study finding as a binary outcome coded as $0=$ "null finding or finding against hypothesized direction" (referent category), $1=$ "positive or partially positive finding", as a function of study-level characteristics using a logistic regression model. The study-level characteristics were entered as main effects as follows: (1) Year of publication; (2) Country of publication $(1=$ US, $2=$ European country, $3=$ Others), (3) risk factor ( $1=$ education, $2=$ smoking, $3=$ alcohol, $4=$ physical activity, $5=$ caffeine, $6=$ antioxi dants, $7=$ homocysteine, $8=n-3$ fatty acids); (4) sample size (when a range was provided, the average was taken), (5) Study participant age group: $1=$ contains ages $<65 y$, $0=$ does not contain ages $<65 y$; (6) Participant gender composition: $1=$ Men only; $2=$ Women only; $3=$ Both; (7) Study design: $1=$ cross-sectional; $2=$ cohort; (8) Number of cognitive outcomes included in the study (e.g. 1 if only incident $\mathrm{AD}$ was the outcome; 2 if it is both incident $\mathrm{AD}$ and incident dementia); (9) General category of cognitive outcome(s): 1 = dementia/AD/impairment; 2 = cognitive function/decline; 3 = both.

\section{Meta-analysis: data points with incident $A D$ and selected risk or protective factors}

Focusing on data points with incident $\mathrm{AD}$ as an outcome, we conducted further meta-analysis to assess the strength of the association between selected risk or protective factors and this outcome. This analysis was thus restricted to 
prospective cohort studies with available data points that had comparable measurements for each risk/protective factor, thus allowing to estimate a pooled measure of association across those data points and studies. The original reported odd ratios (ORs), relative risks (RRs) or Hazard Ratios (HRs) were combined into a pooled value with 95\% confidence interval (CI). The RRs were then pooled using random effects models when included study data points were deemed heterogeneous based on the Q-test for homogeneity $(\mathrm{p}<0.05)$ or fixed effect when study data points were homogenous ( $\mathrm{p}>0.05)$, which are also presented among results. As such, a summary or pooled RR was provided using forest plots and computed by computing the weighted average of the natural logarithm of each relative measure of interest weighting by the inverse of each RR's respective variance [260]. Random effects models that further incorporated between-study variability were conducted using DerSimonian and Laird's methodology.

Considering estimates of exposure prevalence from the largest study with available data on each exposure, we also computed a population attributable risk percentage (PAR\%) by pooling data points from all studies together.

$$
\begin{gathered}
\begin{aligned}
P A R \%_{p, l c l, u c l ; i j} & =\frac{100 \times\left(\operatorname{Pr}_{\exp } \times\left(R R_{p, l c l, u c l ; i j}-1\right)\right)}{1+\left(\operatorname{Pr}_{\exp }\left(R R_{p, l c l, u c l ; i j}-1\right)\right.} \\
= & \left(1-\theta_{i j}\right) \times 100
\end{aligned} \\
\operatorname{Var}\left(\theta_{i j}\right)=\operatorname{Var}\left(1-\theta_{i j}\right)=\left(1-P A R_{p ; i j}\right)^{2} \times \operatorname{Var}\left(\operatorname{Ln}\left(1-P A R_{p ; i j}\right)\right) \\
=\left(1-P A R_{p ; i j}\right)^{2} \times\left(\operatorname{Ln}\left(1-P A R_{l c l ; i j}\right)-\operatorname{Ln}\left(1-P A R_{u c l ; i j}\right) / 3.92\right)^{2}
\end{gathered}
$$

$$
P A R \%_{95 \%} C I ; i j=P A R \%_{p, i j} \pm 1.96 \times \sqrt{\operatorname{Var}\left(\theta_{i j}\right)} \times 100
$$

As shown in Equations 1.1, 1.2 and 1.3, RR (point estimates per study and data point; 95\% CI) was applied to the formula and $\mathrm{Pr}_{\text {exp }}$ was the estimated prevalence of each exposure. The estimation of SE for PAR\% was obtained using the delta method [261].

Finally, in order to examine publication bias, we used Begg's funnel plots; each RR point estimate was plotted against their corresponding standard errors (SE) for each study on a logarithmic scale [262,263], for all exposures combined. This type of bias was also formally tested using the Begg-adjusted rank correlation tests [264] and the Egger's regression asymmetry test [265]. All analyses were conducted with STATA 11.0 (StataCorp, College Station, TX) [266]. Type I error was set at 0.05 for all measures of association.

\section{Results and discussion}

\section{Socio-economic Status (SES) as indicated by education}

Early life conditions are related to cognitive development and abilities in childhood and cognitive function in adulthood. Low educational attainment and other markers of low socio-economic position (SEP) were associated with poorer cognitive function in adulthood and age-related cognitive decline and impairment, as well as greater risk or prevalence of dementia and AD in the elderly. In this study, we focused our attention on education as a maker of SES, given that it is the most commonly studied protective factor.

Several possible mechanisms support the finding that less education is related to cognitive decline: First, education may exert direct effects on brain structure early in life by increasing synapse number or vascularization and creating cognitive reserve. This was named the "reserve capacity" hypothesis. Thus, this hypothesis states that early life conditions affect the pace of cognitive decline in later life [38]. Education in early life may have effects in later life if persons with more education continue searching for mental stimulation ("the use it or lose it" hypothesis), which may lead to beneficial neurochemical or structural alterations in the brain [267]. Indeed, in one study, recent mental stimulation was associated with improved cognitive functioning [268]. Alternatively, education may act through several "behavioral mediators" to improve health in general, and cognitive functioning in particular [267]. This hypothesis was confirmed by a study using the Framingham cohort which suggested that education was uniquely protective against $\mathrm{VaD}$ and not associated with AD [28]. This finding was explained by mediating effects of other risk factors of cognitive decline, including smoking and hypertension, which in turn can initiate cerebrovascular damage. However, Lee and colleagues [52] found evidence contrary to this hypothesis by showing a sustained strong association between education and cognitive functioning after adjustment for behavioral and health-related factors.

Based on our findings (Table 2 and Figure 2A), 18 (66.7\%) of the 27 cohort studies that met our selection criteria found that lower education was linked to a worse cognitive outcome in the overall population and for all studied outcomes, 1 found this relationship with incident $\mathrm{VaD}$ but not $\mathrm{AD}$ [28], 1 found the relationship with cognitive function but not decline [64], 1 concluded that IQ was a better predictor than education [38], and 2 detected a significant association in the hypothesized direction only in women [44] and in ApoE4- individuals [53]. The remaining four cohort studies did not find an association in the hypothesized direction $[26,60,68,71]$.

Note: $+(\mathrm{ALL})=$ positive finding, given hypothesis, for all subjects and most outcomes of interest; +(some outcomes) = positive finding, given hypothesis, for all subjects and some outcomes of interest but not others; +(some groups) $=$ positive finding, given hypothesis, for some groups and most outcomes of interest; $0=$ null finding, given hypothesis; - = finding against hypothesized direction. 


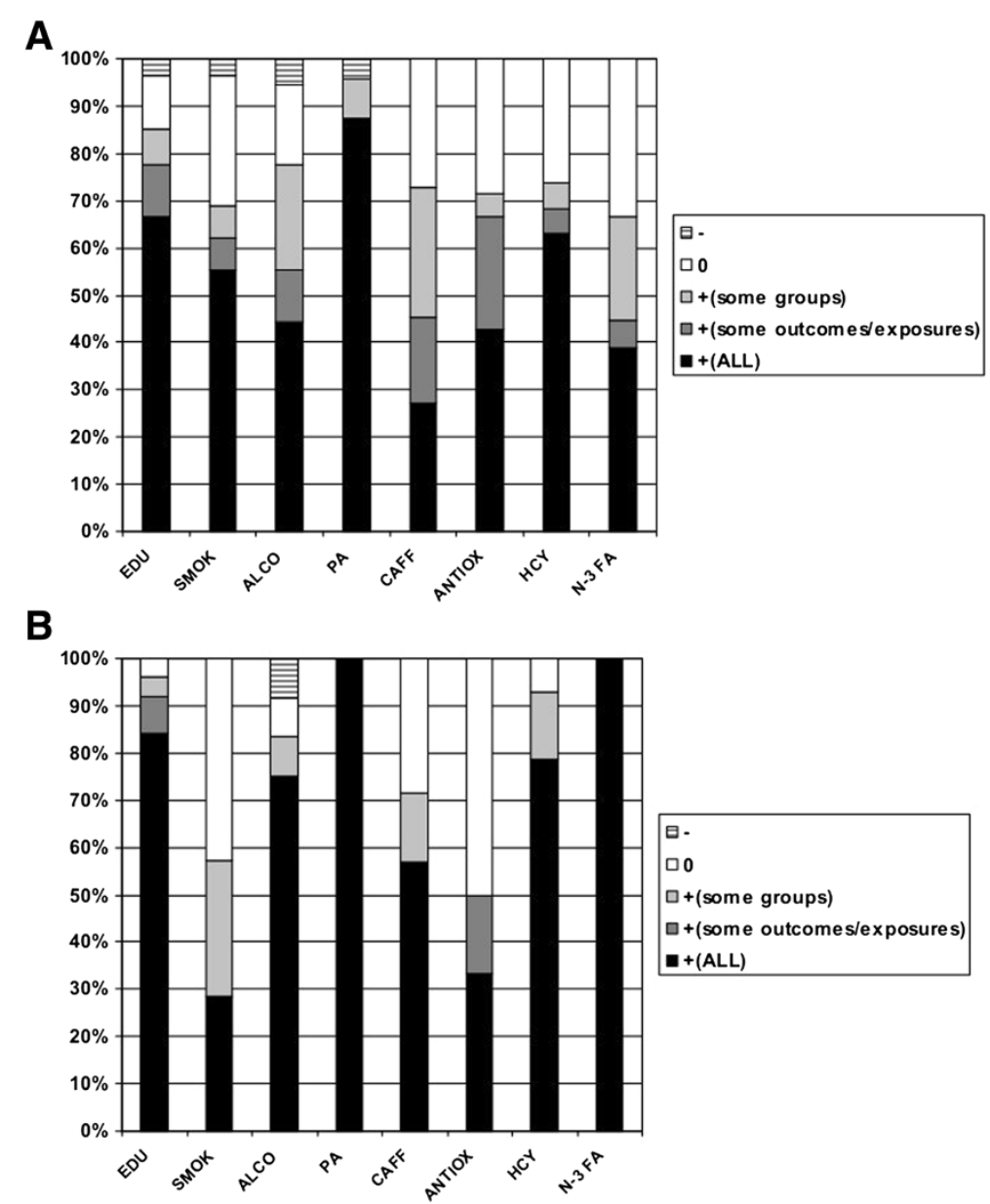

Figure 2 Main findings (\%) of selected studies, given hypothesis: (A) Cohort Studies (B) Cross-sectional studies.

*P-value based on $\chi^{2}$ test for independence between risk factor and finding.

The association between education and the studied cognitive outcomes was in the hypothesized direction, with higher education being protective, for the majority of the selected cross-sectional studies (21 out of 25, $84 \%)$, while 2 found an association with prevalent AD but not $\mathrm{VaD}[41,56], 1$ found that literacy was a better predictor than education [61], and 1 failed to detect a significant association [40] (See Table 2 and Figure 2B).

\section{Behavioral factors}

Several behavioral factors were selected, including smoking, alcohol drinking,and physical activity.

\section{Smoking}

Smoking is a risk factor for several chronic diseases, but its long-term relationship with dementia of various sub-types is still controversial. In fact, smoking is well known to increase the risk of stroke [269] and thus subsequent vascular types of dementia (VaD). However, many studies have concluded that smoking status influenced risk of $\mathrm{VaD}$ independently of stroke status and thus may have an effect beyond cerebrovascular disease. In addition, studies that have shown a direct impact of smoking on $\mathrm{AD}$, suggest that smoking might in fact influence neurodegeneration. A vast amount of literature points to a role of smoking in oxidative stress and inflammation, both mechanisms believed to play a key role in AD [270].

However, it is also biologically plausible that smoking might protect against cognitive decline and $\mathrm{AD}$, given that nicotine, a key active component of tobacco, may enhance the release of acetylcholine, increase the density of nicotnic receptors, therefore improving attention and information processing [271]. It is now known that AD is characterized by cholinergic system deficits which may be delayed through tobacco consumption [271,272].

Population-based evidence of an effect of smoking on cognitive outcomes was inconclusive, with most longitudinal studies reporting weak or null associations $[63,72,74,76,77,82,84,90]$. However, a number of other cohort studies have found a positive association 
between smoking and risk of incident dementia and AD $[78,86,88,93,95,98,101,103,104]$ as well as incident cognitive impairment $[75,81,90]$ and age-related cognitive decline $[83,85,89,96,99,105]$.

For instance, the British 1946 birth cohort study pointed to the difficulty of finding an association between smoking and cognitive impairment given the differential high mortality of smokers especially among the elderly population [85]. After controlling for a range of socioeconomic and health status indicators (both physical and mental), they found that smokers who survive into later life may be at risk of clinically significant cognitive decline. However, these effects were accounted for largely by heavy smokers, i.e. those who smoked 20 cigarettes per day or more. Earlier research on middle aged adults suggested that current smoking and number of pack-years of smoking were related to reduced performance on tests of psychomotor speed and cognitive flexibility assessed approximately five years later [83]. Similar results were shown for cognitive decline in a large cohort study (Rotterdam study) conducted in multiple European countries [89] and in another more recent study conducted in the United States [92].

Among studies that examined incidence of $\mathrm{AD}$ in relation to smoking status, two of the largest European cohort studies reported conflicting results. While one found no relationship between smoking status and incident AD among a large sample of 34,439 older UK men (mean age: 81) [82], the recent 2011 study found that heavy smoking increased the risk of dementia and AD in a younger sample of 21,123 older Finnish adults (Mean age:60.1) that comprised both men and women [104].

In sum, 16 (55.2\%) out of the 29 selected cohort studies linking smoking to the various cognitive outcomes found the relationship to be in the hypothesized direction in the entire population that was studied and for most outcomes of interest [75,81,83,85,86,88,89,92-96,98,99,101,104], while 2 found this relationship for some outcomes but not others $[97,103]$ and 2 detected it for a sub-group of the total population $[78,105]$, while the remaining 9 studies did not find an association $[63,72,74,76,77,82,84,90]$ or found an association in the opposite direction [102]. (See Table 2 and Figure 2A).

Only 2 (28.6\%) of the 7 cross-sectional studies found an association in the hypothesized direction $[36,87]$, while 2 detected it for a sub-group of the total population $[79,100]$, and the remaining 3 did not detect a significant association [73,80,91], (See Table 2 and Figure 2B).

\section{Alcohol}

Alcohol consumption in moderation was hypothesized to be protective against cognitive decline and impairment in old age. Several mechanisms may be involved in explaining the potential protective effect of moderate alcohol consumption on various cognitive outcomes. First, this effect might be mediated through cardiovascular risk factor reduction, partly through a dampening effect of ethanol on platelet aggregation, or through a modification of the serum lipid profile. Second, another potential mechanism in which alcohol can have a direct effect on cognitive function is through acetylcholine release in the hippocampus, which in turn enhances learning and memory [273].

The Rotterdam study [83] also examined the effect of alcohol use on cognition. They found that past alcohol consumption's effect on speed and flexibility appeared to be slightly U-shaped, with the best performance observed among those who drank 1-4 glasses of alcohol per day, although this association was stronger among women than among men. Other studies also detected sex differences $[106,107,111]$. Light to moderate alcohol consumption was also found beneficial based on findings of other cohort and cross-sectional studies with a U- or J-shaped pattern observed [108-110,113,114,116,117,119-121,124-127]. However, in other studies, a linear dose-response relationship between alcohol use and improved cognition was noted, though the authors cautioned that these should not encourage increased alcohol consumption without an upper bound to this consumption $[114,115,122,131]$.

In one cross-sectional study, a linear relationship between alcohol consumption and cognitive function was found in women but a U-shaped pattern was found in men [109]. One cohort study found that overall, moderate consumption was protective against poor cognitive function, but had an opposite relationship with cognitive function among ApoE4 ${ }^{+}$individuals [113], while another found that alcohol use in general was related to better cognition without effect modification by ApoE4 status [123]. Slower memory decline with increased alcohol consumption in men was found in one study, though the opposite relationship was found in the case of psychomotor speed among women [118]. The positive association between alcohol intake and memory was also noted in at least one other crosssectional study for both men and women combined [128]. Moreover, heavy alcohol use was linked to poorer cognitive outcomes in a few studies $[87,127,129,130]$. Finally, only a few studies among those that were selected found no associations between alcohol consumption and cognitive outcomes $[76,77,112]$.

In fact, 8 out of the 18 selected cohort studies (44\%) linking alcohol consumption to the various cognitive outcomes, found the relationship to be in the hypothesized direction (but were U-shaped, J-shaped or linear) in the entire population that was studied and for most outcomes of interest [108,114,116,117,122,124,125,131], while 2 found this relationship for some outcomes but not others $[115,120]$ and 4 detected it for a sub-group of the total population $[83,111,113,118]$. Moreover, 1 cohort studies have indicated that alcohol use was generally linked 
to poor cognitive outcomes for the total population [87]. Finally, 3 did not find any significant associations between alcohol consumption and the various cognitive outcomes that were under study $[76,77,129]$. (See Table 2 and Figure 2A).

9 of the 12 cross-sectional studies (75\%) found an association in the hypothesized direction for the entire study population and for most outcomes of interest $[106,109,110,119,121,123,126-128]$. The remaining 3 studies either found this U-shaped or J-shaped association in a sub-group [107], and either failed to detect any association [112] or detected one that was not in line with the hypothesis, whereby alcohol use was generally found to result in poor cognitive outcomes [130]. (See Table 2 and Figure 2B).

\section{Physical activity}

Physical activity has many well-known benefits for preventing a number of chronic disorders, including coronary heart disease, stroke, diabetes mellitus and osteoporosis. However, its impact on cognitive functioning has not been studied extensively. Several mechanisms may underlie the potentially protective effects of physical activity on cognitive function, including sustained cerebral blood flow [274], improved aerobic capacity and cerebral nutrient supply $[275,276]$ as well as growth factors, specifically the brain-derived neurotropic factor, which is a molecule that increases neuronal survival, enhances learning, and protects against cognitive decline $[277,278]$.

Currently, 24 cohort and 4 cross-sectional studies have examined the hypothesized relationship. For instance, a recent cohort study of 716 dementia-free older adults from the Rush Memory and Aging Project who were followed-up for an average of 4 years found an inverse relationship between total daily physical activity and incident $\mathrm{AD}$ after controlling for age, sex, education, self-report physical, social, and cognitive activities, as well as current level of motor function, depressive symptoms, chronic health conditions, and ApoE4 allele status [156]. Furthermore, a recent cross-sectional study of 9344 women, 65 years and older, found a lower prevalence of cognitive impairment among those who reported being physically active versus those who reported being physically inactive at different stages of their lives [155].

These findings suggested that physical activity could represent an important and potent protective factor for cognitive decline and dementia in elderly persons. Significant findings were obtained by other recent cohort [132-145,147,148,150-154,156-158] and cross-sectional studies $[100,146,149]$. Only one cohort study resulted in non-significant findings [143].

In sum, of the 24 selected cohort studies linking physical activity to the various cognitive outcomes, $21(87.5 \%)$ found the relationship in the hypothesized direction in the entire population that was studied and for most outcomes of interest [132,133,135-140,142,144,145,147,148,150-154, 156-158,279], while 1 found this relationship in ApoE4 carriers [134] and 1 in non-carriers [141]. In one cohort study, the association was against its hypothesized direction [143]. (See Table 2 and Figure 2A).

In addition, all 4 of the selected cross-sectional studies (100\%) found an association in the hypothesized direction for the entire study population and for most outcomes of interest (See Table 2 and Figure 2B).

\section{Nutritional factors}

Nutritional factors being studied in relation to cognitive outcomes included caffeine consumpion, antioxidant nutrients and Hcy. In addition, special attention was devoted recently to one class of essential fatty acids, namely $n-3$ fatty acids.

\section{Caffeine}

Caffeine is known to be the most widely used psychoactive drug worldwide. Its main source is coffee particularly in Western diets. Acting as a stimulant of the central nervous system, caffeine causes heightened alertness and arousal [280]. Previous literature yielded inconsistent findings about the effects of caffeine consumption on cognitive processes. In fact, caffeine improved perceptual speed and vigilance, as well as more complex functions such as memory [281]. Caffeine is one type of compound known as methylxanthines whose effects are mainly to block adenosine receptors in the brain, resulting in cholinergic stimulation. It was hypothesized that such stimulation would lead to improved memory [282]. The earliest large cross-sectional study conducted by Jarvis and colleagues found that caffeine improved cognitive performance [159]. Later on, other cross-sectional studies focusing on tea consumption found similar results [100,162,167,170]. Others, however, did not show evidence of a significant protective effect $[160,168]$. In sum, 4 of 7 selected cross-sectional studies linking caffeine consumption to various cognitive outcomes found the relationship to be in the hypothesized direction in the study population and for most outcomes of interest (57.1\%), one found this association in men [100] and two failed to find a significant association [160,168]. (See Table 2 and Figure 2B).

Of 11 cohort studies, positive findings pertained to 3 $(27.3 \%)[163,164,175]$, though this was found only for coffee intake in two studies [165,169], while 5 recent studies detected this association only among women or for specific exposures [165,169,171-173]. The remaining cohort studies (3 of 11, 27\%) did not find an association between caffeine intake and cognitive change [161] or incident dementia $[166,174]$. Given the paucity of large cohort studies, more research is needed to establish causality (See Table 2 and Figure 2A). 


\section{Antioxidants: focus on vitamin $E$}

Several findings suggest that oxidative stress may play an important role in the pathogenesis of AD. First, the brains of AD patients have lesions that are associated with exposure to free radicals. Moreover, oxidative stress among these patients is also marked by an increased level of antioxidants in the brain that act as free radical scavengers. Finally, in vitro studies suggest that exogenous antioxidants may reduce the toxicity of $\beta$-amyloids in the brains of $\mathrm{AD}$ patients [283-285]. Based on these findings, it may be hypothesized that dietary antioxidants may help reduce the risk of $\mathrm{AD}$.

Those epidemiologic studies examined the longitudinal relationship between supplemental antioxidants and risk of $\mathrm{AD}$ and other dementias found conflicting results: While vitamin $C$ supplement use was related to lower AD risk in one cohort study [178], combined supplementation of vitamin $\mathrm{E}$ and vitamin $\mathrm{C}$ was associated with reduced prevalence and incidence of $\mathrm{AD}$ and cognitive decline in three other cohort studies $[189,193,198]$, whereas another study found this effect to be specific to Vitamin E supplements [186]. These findings of a protective effect of supplemental antioxidant use against cognitive impairment and decline was replicated in a large cohort study [185]. However, there were only borderline or little evidence of a cognitive benefit from use of antioxidant supplements, particularly vitamins $\mathrm{C}$ and $\mathrm{E}$, according to at least five independent cohort studies [177,180,187,192,199].

There are several prospective cohort studies on the effect of dietary antioxidants on the risk of dementia. One study found that high dietary intake of vitamins $C$ and $E$ may reduce the risk of $\mathrm{AD}$ [182] with the relationship most pronounced among smokers. Morris and colleagues [183] found that dietary intake of vitamin $\mathrm{E}$, but not other antioxidants, was associated with a reduced risk of incident $\mathrm{AD}$, although this association was restricted to individuals without the Apolipoprotein E $\varepsilon 4$ genotype. Similar findings were reported with cognitive decline as an outcome [184]. In a later study when both outcomes were considered it was concluded that certain forms of tocopherols not found in dietary supplements but found only in foods may be at play [194]. This observation was corroborated by at least one recent study [197]. Another study, however, suggested that dietary antioxidants were not able to reduce AD risk [187]. Similarly, Laurin and colleagues [188] found no association between midlife dietary intake of vitamins $\mathrm{E}$ and $\mathrm{C}$ and dementia incidence. At least five other cohort studies came to a similar conclusion $[176,181,201,202]$. In addition to examining associations of cognition with vitamins $\mathrm{C}$ and $\mathrm{E}$, other studies found that carotenoids, particularly $\beta$-carotene intake, may be have beneficial effects of various cognitive outcomes [176], though others were not able to detect such an association $[184,201,202]$.
Irrespective of the source of antioxidants, plasma concentration may be a good biomarker for oxidative stress status. In particular, an inverse association between plasma vitamin $\mathrm{E}$ among others and poor cognitive outcomes was found in at least two cross-sectional studies $[179,190]$ and two cohort studies [196,200]. Another cross-sectional study, however, did not find evidence of an association between plasma antioxidants, including vitamin $\mathrm{E}$ and prevalent $\mathrm{AD}$ [191]. In addition, among studies that examined the influence of plasma carotenoids $[179,195]$, only one detected a significant potential protective effect against cognitive impairment [195]. While these results are mixed, they suggest that at least one antioxidant has a protective effect against adverse cognitive outcomes.

In sum, of the 21 selected cohort studies linking antioxidants, with focus on vitamin E, to the various cognitive outcomes, 9 (42.9\%) found the relationship to be in the hypothesized direction in the entire population that was studied and for most outcomes of interest $[176,178,182,184,189,193,194,197,198]$, while 5 found this relationship for specific antioxidants or some outcomes but not others $[180,183,186,196,200,201]$ and 1 detected it for a sub-group of the total population [183]. The remaining selected cohort studies $(n=6)$ did not find a significant association $[177,185,187,188,192,199]$. (See Table 2 and Figure 2A).

Similarly, of the 6 cross-sectional studies that were selected, 2 (33.3\%) found an association in the hypothesized direction for the entire study population and for most outcomes of interest [190,195], 1 found the association to hold only for vitamin E [179], whereas 3 found no significant association [181,191,202]. (See Table 2 and Figure 2B).

\section{Homocysteine}

An elevated level of plasma concentration of the sulfur amino acid Hcy (hyperhomocysteinemia) is recognized as an independent risk factor for cardiovascular, peripheral vascular, and cerebrovascular disease [286]. Accordingly, a potential influence of hyperhomocysteinemia on cognitive functioning among older adults was postulated and several studies were able to associate high levels of Hcy with increased risk of incident AD or all-cause dementia $[206,217,224,228,233,234]$. Studies have pointed to selective effect of Hcy on specific domains of cognition $[214,287,288]$. One explanation could be that Hcy might be affecting certain parts of the brain to a greater extent than others, and studies have linked Hcy to higher degree of white matter hyperintensities and with brain atrophy [289-293].

Even though blood Hcy levels increase with age and diminished renal function, it is largely determined by dietary intake of B-vitamins (mainly B-6 and B-12) and folate which are needed to convert Hcy into methionine 
and cysteine, through the methylation reactions [294]. Thus, Hcy status in plasma can be modified by dietary interventions. Moreover, vitamin B-12 plasma level has been shown to be inversely related to that of Hcy [295] and studies looking at Hcy levels and cognitive functioning also examined the effect of B-vitamins. In particular, vitamin B-12 was found to be protective against decline in at least three recent studies [204,213,219]. At least five other studies [204,213,214,216,217,219,221] concluded that fotate was protective against cognitive impairment or decline. For Vitamin B-6, two other studies suggested a protective effect [213,219]. An antagonistic interaction of folate and Vitamin B-12 with Hcy's effect on cognition was noted in other studies [224,296,297]. Aside from its link to cardiovascular disease, Hcy was shown to have neurotoxic and excitotoxic properties in vitro [298,299], suggesting a direct influence on cognition.

Overall, of the 19 selected cohort studies linking Hcy to the various cognitive outcomes, $12(63.2 \%)$ found the relationship in the hypothesized direction in the entire population that was studied and for most outcomes of interest [206,215,217,219,222-224,228,231,233-235], while 2 found this relationship for some outcomes but not others or a sub-group [213,214] and 5 were not able to detect a significant association [203,209,210,229,230]. (See Table 2 and Figure 2A).

Similarly, of the 14 cross-sectional studies that were selected, $11(78 \%)$ found an association in the hypothesized direction for the entire study population and for most outcomes of interest [204,205,207,208,216,218, 220,221,225,227,232], 1 found an association only among older adults above age 60y [212], 1 detected it among ApoE4 ${ }^{+}$individuals [226], and 1 found no significant relationship [211]. (See Table 2 and Figure 2B).

\section{n-3 fatty acids}

Another nutritional factor hypothesized to be protective against cognitive decline is higher intake of $n-3$ fatty acids and/or a better balance of $n-3 / n-6$ fatty acids. Linoleic(LA 18:2n-6) and $\alpha$-linolenic (LNA 18:3n-3) are two types of fatty acids that are essential for all members of the animal kingdom. These fatty acids and their respective derivatives are also commonly referred to as $n-6$ and $n-3$ fatty acids. Their essentiality lies in the fact that they cannot be synthesized de novo within the human or animal organism [300].

In the past, $n-3$ fatty acids were classified only as essential because of their ability to alleviate deficiency symptoms that include dermatitis, growth retardation and reproductive failure. However, $n-3$ fatty acids have other important neurological functions, which explain their high concentrations in neural and retinal tissues [301-303]. Some of the longer chain fatty acids that are synthesized from $\alpha$-linolenic acid include Eicosapentanoic acid (EPA 20:5 n-3), which through further elongation, desaturation and $\beta$-oxidation produces Docosahexaenoic acid (DHA 22:6 n-3). On the other hand, products of linoleic acid which are also termed long-chain $n-6$ fatty acids include gamma-linoleic (GLA 18:3 n-6), dihomogammalinolenic acid (DGLA 20:3 $n-6$ ) and Arachidonic acid (AA 20:4 n-6) [304]. Of all organs in the human body (excluding adipose tissue), the nervous system has the highest lipid content. The dry weight of an adult brain is $50 \%$ to $60 \%$ lipid, and $35 \%$ of the lipid content is accounted for by polyunsaturated fatty acids (PUFAs) [305].

A review of scientific articles and biochemistry textbooks [306] suggested that the fatty acid composition of neuronal cell membrane phospholipids reflects their intake in the diet. Fish oils, which contain high levels of C20 and C22 PUFA, exert the most profound influence on brain PUFA concentrations [306]. The ratio between $n-3$ and n-6 PUFA may influence various aspects of serotoninergic and catecholaminergic neurotransmission, and it has been shown that by increasing the density of neurotransmitter receptors for acetylcholine and dopamine, dietary $n-3$ PUFA can improve learning and memory processes [307].

Previous observational studies suggested that the biochemical composition of blood components in terms of fatty acids differs significantly between subjects with normal cognitive functioning and patients with some form of cognitive impairment. While the majority of these studies showed an inverse association of plasma and erythrocyte $n-3$ fatty acids with cognition among older adults [243-245,248,255,258], at least one found no association between biochemical markers of $n-3$ fatty acids and cognition [251].

Epidemiological studies involving self-reported dietary data of $n-3$ fatty acids had suggestive but slightly controversial results. One study by Morris and colleagues used cohort data on 815 subjects who were initially unaffected by $\mathrm{AD}$ (age range: $65-94 \mathrm{y}$, mean follow-up period $=2.3 \mathrm{y}$ ). Using standardized criteria, AD incidence was compared across $n-3$ fatty acid consumption groups, with those eating fish once per week compared to those who rarely or never eat fish having considerably lower incidence ( $\mathrm{RR}=0.4 ; 95 \%$ CI: $0.2,0.9)$. Total $n-3$ fatty acid consumption was also associated with a reduced AD risk even after controlling for intake of other dietary fats, vitamin $\mathrm{E}$ and for cardiovascular conditions [239]. A similar finding was reported later on for a larger but comparable cohort when looking at fish consumption and cognitive decline over time [241].

In the Zutphen Elderly Study, cognitive functioning and decline over three years were assessed in a cohort of 476 men aged 69-89y using the Mini-Mental State Examination (MMSE). Findings indicated that high linoleic 
acid intake (the main $n-6$ fatty acid in the diet) was associated with cognitive impairment, even after controlling for age, education, cigarette smoking, alcohol consumption and energy intake (OR $=1.76,95 \% \mathrm{CI}$ : 1.04-3.01, comparing highest to lowest tertile). However, there was no distinctive association for $n-3$ fatty acids. Nevertheless, total fish consumption was suggestive of a protective effect, even though it did not reach significance [236].

Another larger cohort study-The Rotterdam Studyrecruited 5,386 non-institutionalized participants, aged $55+\mathrm{y}$ at baseline, who had normal cognition and assessed their complete dietary intake with a semi-quantitative food-frequency questionnaire. After an average 2.1y of follow-up, lower risk of incident dementia and AD was found among fish consumers and therefore among those with higher intake of $n-3$ fatty acids $(R R=0.3$; 95\% CI: 0.1-0.9) [237]. However, when the study was conducted later with a longer follow-up (mean follow-up period of 6.0 years), it was concluded that high intake of total, saturated, trans fat, cholesterol and low intake of monounsatured fatty acids (MUFA), total PUFA, $n-6$ PUFA and $n$ - 3 PUFA were not associated with increased risk of dementia or its subtypes [238].

A cross-sectional study of 1,613 subjects aged 45-70 years that examined the association between fatty acid and fish intake with cognitive function, found that the risk of cognitive impairment was reduced with increased consumption of fatty fish and marine $n$ - 3 PUFA. per Standard Deviation (SD) increased intake, the ORs were 0.81 (95\% CI: $0.66,1.00)$ and 0.72 (95\% CI: 0.57, 0.90), respectively [240]. Another recent study using the Athersclerosis Risk in Communities (ARIC) cohort data suggested that dietary intake of $n-3$ fatty acids (mainly DHA + EPA) reduced the risk of cognitive decline in verbal fluency but not other cognitive domains (i.e. delayed word recall and psychomotor speed). This protective effect was particularly strong among hypertensive subjects [246]. The potentially protective effect of dietary $n-3$ fatty acid was also reported in several other large epidemiological studies [242,247,249,253,254,256-258], but not in others [250-252].

In sum, 7 out of the 18 (39\%) selected cohort studies linking $n-3$ fatty acids to the various cognitive outcomes found the relationship in the hypothesized direction in the entire population that was studied and for most outcomes of interest [237,239,247,248,250,253,257], while 1 found this relationship for some outcomes but not others [245], 4 detected it for a sub-group of the total population [242,243, 246,258], and 6 found no association [236,238,241,250-252] (See Table 2 and Figure 2A). In addition, all of the 5 (100\%) cross-sectional studies that were selected found an association in the hypothesized direction for the entire study population and for most outcomes of interest [240,244,249,254,255] (See Table 2 and Figure 2B).

\section{Description of study-level characteristics and comparison by risk factor}

Table 3 shows descriptive findings of study-level characteristics and compares their distributions across risk factors. Out of the 247 selected studies, 98 were conducted in the US (39.7\%), while 104 were carried out in a European country (42.1\%), and the remaining 45 studies originated from Asia, Canada and Australia among others (18.2\%). The majority of the selected studies were cohort studies $(n=167)$. Most had only one type of cognitive outcome (72.5\%), whereas $24.3 \%$ had two, and the remaining $3.2 \%$ had 3 or 4 outcomes. 152 studies had confirmed positive findings for most outcomes, exposures and for all study sub-groups (61.5\%), while $18.2 \%(n=45)$ had null findings. Partially positive findings were found in around $18.2 \%$ while $2 \%$ had a finding against the hypothesized direction. Around $40.5 \%$ of studies included participants with ages $<65 \mathrm{y}$, and the majority had both men and women (84.2\%). Incident $\mathrm{AD}$ as an outcome was available in 47 studies, while 47 studies included incident dementia as a main outcome of interest. On the other hand, cognitive function as an outcome was found in 83 of included studies, while 62 of those studies had cognitive decline or change as a primary outcome of interest (data not shown). In general, there was an almost even split between studies focusing on cognitive function/decline/change (51.0\%) and studies focused on $\mathrm{AD} /$ dementia/impairment as outcomes (46.2\%). Only $2.8 \%$ of the studies examined both categories. When comparing the distribution of those study-level characteristics by risk factor, we found some significant differences for year of publication, country, age group inclusion/exclusion, study design, cognitive outcome type and study finding. In particular, studies on education and cognitive outcomes tended to be published earlier than studies of other risk factors, there were significantly more European studies of n-3 FA compared to other risk factors, while most studies with PA excluded middle aged adults unlike other risk factors. The highest proportion of cohort studies was also found for PA. The vast majority of studies on alcohol and cognitive outcomes used cognitive function/ decline as their primary outcome of interest, unlike other risk factors which were more balanced in terms of cognitive outcome type. The percent positive finding was highest among PA studies (89.3\%) and lowest for caffeine studies (38.9\%). The significant difference in percent "positive finding" was found in cohort studies $(\mathrm{p}=0.043)$ rather than cross-sectional studies $(\mathrm{p}=0.09)$ (See Figure 2A-B).

\section{Consistency analysis: study-level characteristics and risk factor as predictors of study finding}

In an attempt to examine heterogeneity in findings across risk factors and study-level characteristics, we conducted 
Table 3 Study-level characteristics distribution, overall and comparison across risk factors

\begin{tabular}{|c|c|c|c|c|c|c|c|c|c|c|c|c|c|c|c|c|c|c|c|}
\hline \multirow[b]{3}{*}{ Year, Mean (SD) } & \multirow{2}{*}{\multicolumn{2}{|c|}{$\begin{array}{l}\text { Overall } \\
\mathrm{N}=247\end{array}$}} & \multirow{2}{*}{\multicolumn{2}{|c|}{$\begin{array}{l}\text { EDU } \\
\mathrm{N}=52\end{array}$}} & \multirow{2}{*}{\multicolumn{2}{|c|}{$\begin{array}{l}\text { SMOK } \\
\mathrm{N}=36\end{array}$}} & \multirow{2}{*}{\multicolumn{2}{|c|}{$\begin{array}{l}\text { ALCO } \\
\mathrm{N}=30\end{array}$}} & \multirow{2}{*}{\multicolumn{2}{|c|}{$\begin{array}{l}\mathrm{PA} \\
\mathrm{N}=\mathbf{2 8}\end{array}$}} & \multirow{2}{*}{\multicolumn{2}{|c|}{$\begin{array}{l}\text { CAFF } \\
\mathrm{N}=18\end{array}$}} & \multirow{2}{*}{\multicolumn{2}{|c|}{$\begin{array}{l}\text { ANTIOX } \\
\mathrm{N}=27\end{array}$}} & \multirow{2}{*}{\multicolumn{2}{|c|}{$\begin{array}{l}\mathrm{HCY} \\
\mathrm{N}=33\end{array}$}} & \multirow{2}{*}{\multicolumn{2}{|c|}{$\begin{array}{l}\mathrm{N}-\mathrm{FA} \\
\mathrm{N}=23\end{array}$}} & \multirow{3}{*}{$\begin{array}{l}P^{*} \\
<0.001\end{array}$} \\
\hline & & & & & & & & & & & & & & & & & & & \\
\hline & 2004.5 & (5.1) & 2001.3 & (6.3) & 2003.6 & $(5.2)$ & 2004.5 & $(4.5)$ & 2006.7 & (3.6) & 2007.7 & $(4.5)$ & 2003.8 & (3.8) & 2006.2 & (3.1) & 2006.9 & $(4.0)$ & \\
\hline \multicolumn{20}{|l|}{ Country, N (\%) } \\
\hline US & 98 & $(39.7)$ & 16 & (30.8) & 12 & $(33.3)$ & 15 & $(50.0)$ & 17 & (63.0) & 3 & $(16.7)$ & 17 & (63.0) & 13 & (39.4) & 5 & $(21.7)$ & 0.020 \\
\hline Europe & 104 & $(42.1)$ & 22 & $(42.3)$ & 18 & $(50.0)$ & 9 & $(30.0)$ & 8 & (28.6) & 10 & (55.6) & 8 & $(29.6)$ & 14 & $(42.4)$ & 15 & $(65.2)$ & \\
\hline Other & 45 & $(18.2)$ & 14 & (26.9) & 6 & $(16.7)$ & 6 & $(20.0)$ & 3 & $(10.7)$ & 5 & $(27.8)$ & 2 & $(7.4)$ & 6 & $(18.2)$ & 3 & $(13.00$ & \\
\hline \multicolumn{20}{|l|}{ Age group, N (\%) } \\
\hline Excludes $<65 y$ & 147 & $(59.5)$ & 31 & (59.6) & 17 & $(47.2)$ & 13 & (43.3) & 24 & (85.7) & 12 & $(66.7)$ & 20 & $(74.1)$ & 16 & $(48.5)$ & 14 & $(60.9)$ & 0.012 \\
\hline Includes $<65 y$ & 100 & $(40.5)$ & 21 & $(40.4)$ & 19 & $(52.8)$ & 17 & $(56.7)$ & 4 & $(14.3)$ & 6 & (33.3) & 7 & (25.9) & 17 & $(51.5)$ & 9 & $(39.1)$ & \\
\hline \multicolumn{20}{|l|}{ Sex, N (\%) } \\
\hline Both & 208 & (84.2) & 47 & (90.4) & 28 & (77.8) & 28 & $(93.4)$ & 19 & (67.9) & 16 & (88.9) & 22 & (81.5) & 28 & (84.8) & 20 & $(87.0)$ & 0.12 \\
\hline Men only & 26 & $(10.5)$ & 3 & (5.8) & 8 & (22.2) & 1 & (3.3) & 5 & $(17.9)$ & 2 & $(11.1)$ & 2 & $(7.4)$ & 3 & $(9.1)$ & 2 & (8.7) & \\
\hline Women only & 13 & (5.3) & 2 & (3.8) & 0 & $(0.0)$ & 1 & (3.3) & 4 & $(14.3)$ & 0 & $(0.0)$ & 3 & $(11.1)$ & 2 & (6.1) & 1 & $(4.3)$ & \\
\hline \multicolumn{20}{|l|}{ Study design, N (\%) } \\
\hline Cross-sectional & 80 & $(32.4)$ & 25 & $(48.1)$ & 7 & $(19.4)$ & 12 & $(40.0)$ & 4 & $(14.3)$ & 7 & $(38.9)$ & 6 & $(22.2)$ & 14 & $(42.4)$ & 5 & $(21.7)$ & 0.012 \\
\hline Cohort & 167 & (67.6) & 27 & (51.9) & 29 & (80.6) & 18 & $(60.0)$ & 24 & $(85.7)$ & 11 & $(61.1)$ & 21 & $(77.8)$ & 19 & $(57.6)$ & 18 & $(78.3)$ & \\
\hline Sample size, Mean (SD) & 3,561 & $(5,128)$ & 4,345 & $(6,066)$ & 4,745 & $(6,859)$ & 4,745 & $(6,808)$ & 3,322 & $(3,927)$ & 2,408 & $(2,385)$ & 3,643 & $(4,191)$ & 1,074 & (769) & 3,061 & $(3,389)$ & 0.05 \\
\hline \multicolumn{20}{|l|}{ Cognitive outcome count, N (\%) } \\
\hline 1 & 179 & $(72.5)$ & 34 & $(65.4)$ & 26 & $(86.7)$ & 26 & $(86.7)$ & 20 & $(71.4)$ & 14 & $(77.8)$ & 22 & $(81.5)$ & 21 & (63.6) & 15 & $(65.2)$ & 0.77 \\
\hline 2 & 60 & (24.3) & 15 & (28.8) & 4 & $(13.3)$ & 4 & (13.3) & 7 & (25.0) & 3 & $(16.7)$ & 4 & $(14.8)$ & 10 & $(30.3)$ & 8 & $(34.8)$ & \\
\hline 3 & 5 & (2.0) & 2 & (3.9) & 0 & $(0.0)$ & 0 & $(0.0)$ & 1 & (3.6) & 1 & (5.6) & 0 & $(0.0)$ & 1 & (3.0) & 0 & $(0.0)$ & \\
\hline 4 & 2 & $(1.2)$ & 1 & (1.9) & 0 & $(0.0)$ & 0 & $(0.0)$ & 0 & $(0.0)$ & 0 & $(0.0)$ & 1 & (3.7) & 1 & (3.0) & 0 & $(0.0)$ & \\
\hline Cognitive outcome type, N (\%) & & & & & & & & & & & & & & & & & & & 0.042 \\
\hline AD/dementia/impairment & 114 & $(46.2)$ & 26 & $(50.0)$ & 20 & (55.6) & 6 & $(20.0)$ & 16 & $(57.1)$ & 5 & $(27.8)$ & 15 & $(55.6)$ & 15 & $(45.5)$ & 11 & $(47.8)$ & \\
\hline Cognitive function/decline & 126 & $(51.0)$ & 25 & $(48.1)$ & 16 & (44.4) & 24 & $(80.0)$ & 10 & $(35.7)$ & 11 & $(61.1)$ & 12 & $(44.4)$ & 17 & $(51.5)$ & 11 & $(47.8)$ & \\
\hline Both & 7 & (2.8) & 1 & (1.9) & 0 & $(0.0)$ & 0 & $(0.0)$ & 2 & $(7.1)$ & 2 & $(11.1)$ & 0 & $(0.0)$ & 1 & (3.0) & 1 & (4.4) & \\
\hline Study finding, N(\%) & & & & & & & & & & & & & & & & & & & 0.004 \\
\hline Against hypothesis & 5 & (2.0) & 1 & (1.9) & 1 & (2.8) & 2 & (6.7) & 1 & (3.6) & 0 & $(0.0)$ & 0 & $(0.0)$ & 0 & $(0.0)$ & 0 & $(0.0)$ & \\
\hline Null & 45 & $(18.2)$ & 4 & (7.7) & 11 & (30.6) & 4 & (13.3) & 0 & $(0.0)$ & 5 & $(27.8)$ & 9 & (33.3) & 6 & $(18.2)$ & 6 & $(26.1)$ & \\
\hline Positive & 152 & $(61.5)$ & 39 & $(75.0)$ & 18 & $(50.0)$ & 17 & $(56.7)$ & 25 & (89.3) & 7 & $(38.9)$ & 11 & $(40.7)$ & 23 & $(69.7)$ & 12 & $(52.2)$ & \\
\hline Partially positive (outcomes/exposures) & 21 & (8.5) & 6 & $(11.5)$ & 2 & (5.6) & 2 & (6.7) & 0 & $(0.0)$ & 3 & $(16.7)$ & 2 & $(7.4)$ & 1 & (3.0) & 1 & $(4.3)$ & \\
\hline Partially positive (sub-groups) & 24 & (9.7) & 2 & $(7.7)$ & 4 & $(11.1)$ & 5 & $(16.7)$ & 2 & (7.1) & 3 & $(16.7)$ & 5 & (27.8) & 3 & $(9.1)$ & 4 & (17.4) & \\
\hline
\end{tabular}

*P-value for difference across risk/protective factors was obtained from one-way ANOVA test when variable is continuous and $x^{2}$ test when variable is categorical. 
a consistency analysis using a logistic regression model (Table 4). Examining the odds ratios and their 95\% CI, taking "null finding/against hypothesis finding" as the referent category for the outcome, we found that in general, a positive or partially positive finding was significantly more likely when the risk factor was "education" particularly when compared to smoking, caffeine and antioxidants/vitamin E $(p<0.05)$. None of the other study-level characteristics were associated with the study finding.

\section{Meta-analysis: selected risk factors for incident AD}

Using random effects models, we pooled findings of 31 selected data points from 31 studies in which the outcome was incident $\mathrm{AD}$ and for which exposure data was adequate and comparable across studies (Figure 3A-E). Among studies used to summarize the association between

Table 4 Multiple logistic regression: study-level predictors of study finding*

\begin{tabular}{|c|c|c|c|}
\hline & Odds Ratio & $(95 \% \mathrm{Cl})$ & P-value \\
\hline Year & 1.06 & $(0.98 ; 1.14)$ & 0.13 \\
\hline \multicolumn{4}{|l|}{ Country } \\
\hline US & 1.00 & & \\
\hline Europe & 0.96 & $(0.45 ; 2.06)$ & 0.92 \\
\hline Other & 0.99 & $(0.35 ; 2.80)$ & 0.99 \\
\hline \multicolumn{4}{|l|}{ Age group } \\
\hline Excludes $<65 y$ & 1.00 & & \\
\hline Includes $<65 y$ & 0.80 & $(0.40 ; 1.60)$ & 0.53 \\
\hline \multicolumn{4}{|l|}{ Study design } \\
\hline Cross-sectional & 1.00 & & \\
\hline Cohort & 0.60 & $(0.27 ; 1.33)$ & 0.21 \\
\hline Sample size & 1.00 & $(0.99 ; 1.00)$ & 0.25 \\
\hline Cognitive outcome count & 1.03 & $(0.54 ; 1.98)$ & 0.92 \\
\hline \multicolumn{4}{|l|}{ Cognitive outcome type } \\
\hline AD/dementia/impairment & 1.00 & & \\
\hline Cognitive function/decline & 1.52 & $(0.72 ; 3.22)$ & 0.27 \\
\hline Both & 1.78 & $(0.16 ; 19.7)$ & 0.64 \\
\hline \multicolumn{4}{|l|}{ Risk factor } \\
\hline EDU & 1.00 & & \\
\hline SMOK & 0.21 & $(0.06 ; 0.70)$ & 0.012 \\
\hline ALCO & 0.33 & $(0.08 ; 1.29)$ & 0.11 \\
\hline PA & 2.49 & $(0.26 ; 24.29)$ & 0.43 \\
\hline CAFF & 0.18 & $(0.04 ; 0.84)$ & 0.029 \\
\hline ANTIOX & 0.20 & $(0.06 ; 0.75)$ & 0.016 \\
\hline $\mathrm{HCY}$ & 0.41 & $(0.10 ; 1.67)$ & 0.22 \\
\hline$N-3 F A$ & 0.25 & $(0.06 ; 1.05)$ & 0.06 \\
\hline
\end{tabular}

*Positive or partially positive finding coded as "1", Null or against hypothesized finding coded as " 0 " (referent category). Gender composition of the sample was excluded as a predictor due to lack of variability. low education and incident $\mathrm{AD}$, the largest study $(\mathrm{N}=$ 3,675 ) found a $H R=1.81$ with $95 \% \mathrm{CI}: 1.30-2.53$, with a prevalence of low education being $\sim 32 \%$ [43]. In all four studies, the exposure definition was standardized as a comparison between $<8 y$ of education vs. $\geq 8 y$. In contrast, for all other exposures, definitions differed to some extent between studies but were assumed to operationalize the same concept. For instance, high vs. low physical activity was defined as a frequency of 3 times or more per week by two studies, 2 times of more per week by one, 4 activities per week by one, $\geq 2$ vs. $<2$ mile walk/day by another study, and other comparable definitions by the remaining four studies combining frequency and intensity of activity. A full description of how various exposures were defined under Figure 3A-E notes.

Sources: $[28,33,43,46,78,82,86,88,93,95,101,103,104,133$, 137,141,142,145,148,150,156,206,209,215,217,233,237,239, 242,250,251]: Notes: Only studies with available data points on incident AD were selected. Moreover, risk factors/protective factors needed to be measured in a comparable manner across studies to allow for estimating a pooled RR with a 95\% CI. For education, only four studies out of 27 cohort studies had the required inclusion criteria. For smoking status, the common referent category was non-smoking or never smoking or « never or former » whereas exposed group consisted of either " ever smokers » $[78,93]$, or a pooled value for RR to obtain an approximate " ever smoker » category [86], or current smokers $[82,88,95]$, or mid-life smoking or heavy smoking $[101,103,104]$. For high vs. low physical activity level, two studies used the cut-point of 3 or more times per week $[133,145]$, one used 2 times or more per week [142], one used the criterion of 4 activities per week vs. none [141], one used $>=2$ vs. $<2$ miles walking/day [137], and the remaining four studies used other definitions related to both frequency and intensity $[148,150,156]$. For high vs. low n-3 fatty acids, one study had fish consumption (yes vs. no) as the exposure of interest [237], another examined quintiles of total $n-3$ PUFA and compared the fifth to the first quintile in terms of risk for AD [239], a third study had one main exposure as « weekly consumption of fish vs. not » [242], a fourth study contrast high vs. no fish intake, 0-8y follow-up [250], and finally upper quartile vs. lowest quartile for total n-3 PUFA in erythrocyte membranes [251]. For high vs. low Hcy, two studies used a cut-point of $14.6 \mu \mathrm{mol} / \mathrm{L}$ [206,215], one study used a cut-point of $15 \mu \mathrm{mol} / \mathrm{L}$ [217], one study used upper vs. lowest quartile [209] and one study used upper tertile vs. lowest tertile [233].

Tests of heterogeneity, including the Q-tests, determined whether to use fixed-effects or random-effects models to pool the RR. Findings indicated that, with the exception of education and smoking as main exposures, 


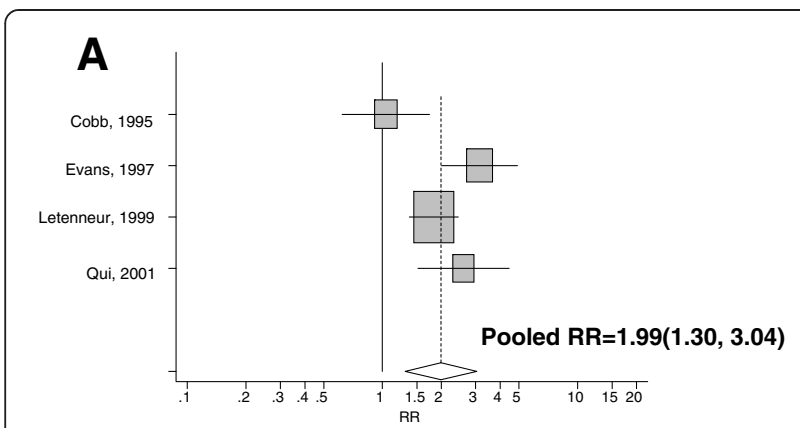

Education (low $<8 \mathrm{y}$ vs. high $>=8 \mathrm{y}$ ) and risk of incident $A D$

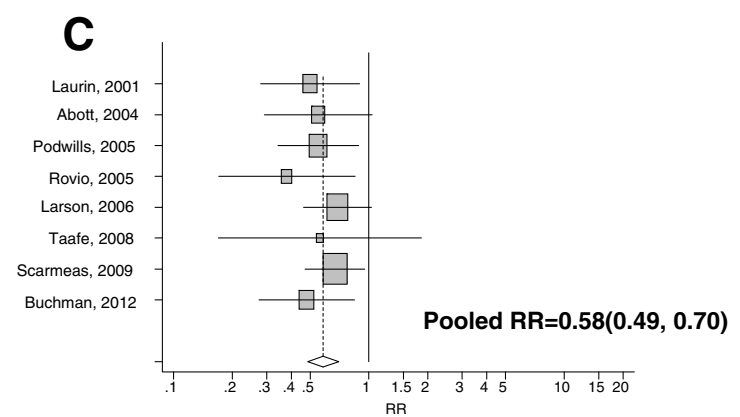

Physical activity (high vs. low) and risk of incident AD

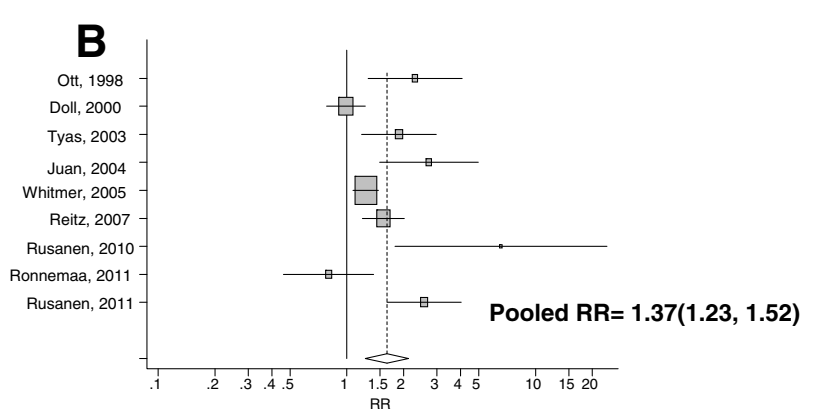

Smoking status (current or ever vs. never) and risk of incident AD

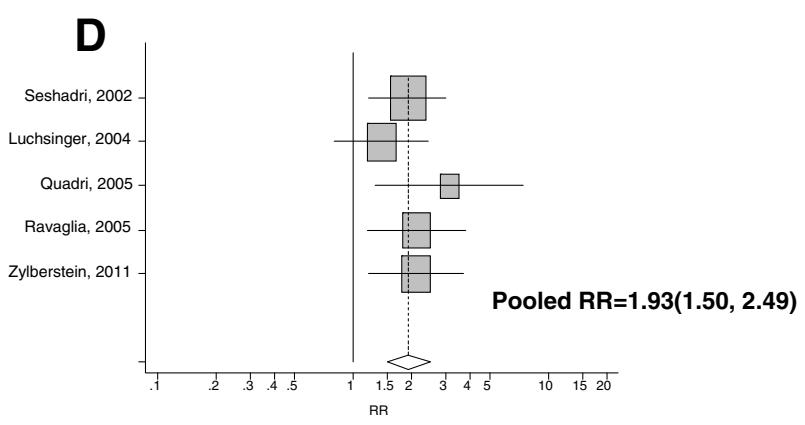

Homocysteine (high vs. low) and risk of incident AD

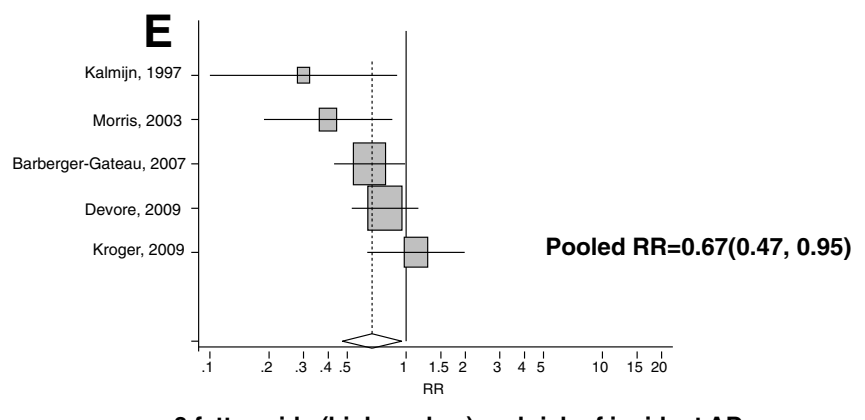

n-3 fatty acids (high vs. low) and risk of incident AD

Figure 3 Meta-analysis of selected risk and protective factors for incident AD ( $\mathbf{n}=\mathbf{3 1})$. (A) Education. (B) Smoking status. (C) Physical activity. (D) Homocysteine. (E) n3 fatty acids.

RR estimates obtained from individual studies were largely homogenous. In sum, the pooled RRs were: 1.99 (1.30, 3.04) for low vs. higher educational attainment $(\mathrm{n}=4$ data points; $\mathrm{Q}=11.33, \mathrm{p}=0.010)$; $1.37(1.23-1.52)$ for smoking status (current or ever vs. never smokers $(\mathrm{n}=9$ data points, $\mathrm{Q}=36.2, \mathrm{p}<0.001)$; $0.58(0.49,0.70)$ for physical activity $(\mathrm{n}=8$ data points, $\mathrm{Q}=3.2, \mathrm{p}=0.867), 0.67$ $(0.47,0.96)$ for high intake of $n-3$ fatty acids $(n=5, Q=7.4$, $\mathrm{p}=0.116)$, and $\mathrm{RR}=1.93(1.50,2.49)$ for high levels of plasma Hcy $(\mathrm{n}=5$ data points; $\mathrm{Q}=2.64, \mathrm{p}=0.620)$.

Taking the largest study for each as a means to obtain an estimate of exposure prevalence, the following was found: low education (32\%) [43], mid-life smoking (59.8\%) [93], lower physical activity (62\%) [150], lower $n-3$ fatty acids (49.4\%) [242], elevated Hcy (30\%) [206]. From these exposure prevalence estimates $\left(\operatorname{Prev}_{\text {exp }}\right)$, we computed the PAR\% and its $95 \% \mathrm{CI}$ to assess the proportion of $\mathrm{AD}$ that is attributable to each exposure in a typical adult population and thus the \% that can be averted if that exposure was eliminated from that population. Our findings indicated that the PAR\% for low education was $24.0 \%$ with a 95\% CI: 8.4-39.6; for mid-life smoking it was $31.0 \%$ with a 95\% CI: 17.9-44.3; for physical activity (lower vs. higher) it was $31.9 \%$ with $95 \%$ CI: $22.7-41.2$; for high vs. low Hcy, it was $21.7 \%$ with a $95 \%$ CI: $12.8-30.6$; for lower vs. higher fish consumption (<weekly vs. $\geq$ weekly), it was $21.9 \%$ with 95\% CI:4.7-39.1.

Publication bias for the meta-analysis data points $(\mathrm{n}=31)$ was assessed using primarily the funnel plot which plotted point estimates of RR for all exposures 
combined on the $\log _{\mathrm{e}}$ scale against their standard errors. This plot indicated that estimates obtained from those 31 studies lay within the pseudo $95 \%$ confidence limits, an indication of non-appreciable publication bias. This finding was reinforced by a non-significant Begg-adjusted rank correlation test $(Z=0.25 ; P=0.80)$, and by Egger's regression asymmetry test (bias $(\mathrm{SE})$ : $-0.43(0.98) ; \mathrm{p}=0.66)$ (Additional file 1: Figure S1).

\section{Discussion}

As stated earlier, this is the first study to systematically review those selected modifiable risk and protective factors for cognitive health outcomes in cross-sectional and cohort studies while comparing the consistency of association between those factors and across study-level characteristics. It is also among few recent studies to compare the strength of association across those factors in relation to incident AD using a similar approach $[19,20]$. However, our study has a few limitations. First, the literature search was limited to published articles in English available in the Medline database. Second, comparing all included studies in a quantitative meta-analytic manner was not possible due to the diversity of the cognitive outcome measurements between original studies included. In fact, cognitive measures included scores from batteries of different cognitive tests, single global cognitive test scores such as the MMSE total score, as well as the use of a factor analytic approach to combine test scores into various domains of interest (e.g. memory, spatial, psychomotor, executive function, attention). Thus, meta-analysis was only possible for measures of cognitive impairment (i.e. MCI, all-cause dementia, $\mathrm{AD}, \mathrm{VaD}$ ) from which we selected incident $\mathrm{AD}$ as the most comparable outcome across studies. However, in order to measure consistency across the selected studies and compare risk factors in terms of consistency, we conducted another type of analysis in which a qualitative outcome of "study finding" was modeled against study-level characteristics. The qualification of a finding as null or positive was based on the main conclusion of each study that was included. This type of analysis does not necessarily discriminate between null findings due to low power, poor quality study $v s$. actual null finding. However, our logistic regression analysis indicated that overall, sample size was not a determining factor for the study finding outcome. Combining findings from meta-analysis and the consistency analyses, we compared evidence level for each risk and protective factor of cognitive health. Other limitations include the lack of comparability in measurements of risk or protective factors in studies with incident $A D$, which resulted in the exclusion of a few data points in our meta-analysis. However, the datapoints that were included in the meta-analysis were relatively comparable as described in the footnotes of Figure 3A-E. Finally, our study was limited by the inability to create a common quality measure for all studies given the diversity of the exposure variables and the relative importance of having a large sample size given the type of exposure (e.g., a larger sample size is needed for a questionnaire-based exposure vs. a blood level based exposure).

Our review shows that over the past several decades many risk or protective factors have been studied in relation to cognitive impairment, dementia (including AD) and cognitive decline. Overall, these studies indicate that modifiable factors including individuals' socio-economic, behavioral characteristics and dietary intake seem to affect people's cognitive ability and change over time, as well as the incidence of cognitive impairment, all-cause dementia and AD. It is worth noting, however, that some of the diagnostic criteria for dementia, AD and MCI have changed over time, particularly between the 1990s and the more recent years, as shown in Table 1.

In total, 247 studies were retrieved for systematic review. When conducting consistency analysis for each risk factor/ design dyad, we found the \% of studies with positive finding, given hypothesis, for most outcomes and study participants to range from $\sim 38.9 \%$ for caffeine $(27.3$ for cohort studies $(\mathrm{n}=11), 57.1 \%$ for cross-sectional studies $(\mathrm{n}=7)$ ) to $\sim 89 \%$ for physical activity $(87.5 \%$ for cohort studies $(n=24) ; 100 \%$ for cross-sectional studies $(n=4)$ ). Consistency analysis confirmed that education-related studies had a significantly higher propensity for a positive or partially positive finding compared to caffeine, smoking and antioxidant-related studies. Meta-analysis of 31 studies with incident $\mathrm{AD}$ and selected risk/protective factors yielded pooled $\mathrm{RR}$ and 95\% CI as follows: $\mathrm{RR}=1.99$ (1.30, 3.04) for low(risk factor) vs. higher education ( $\mathrm{n}=4$ studies; $\mathrm{Q}=11.33, \mathrm{p}=0.010) ; \mathrm{RR}=1.37(1.23,1.52)$ for smoking status (current or ever(risk factor) vs. never smokers $(\mathrm{n}=9$ studies, $\mathrm{Q}=36.2, \mathrm{p}<0.001)$; $\mathrm{RR}=0.58(0.49,0.70)$ for higher physical activity(protective factor) vs. lower ( $\mathrm{n}=8$ studies, $\mathrm{Q}=3.2, \mathrm{p}=0.867), \mathrm{RR}=0.67(0.47,0.96)$ for higher intake of $n-3$ fatty acids(protective factor) vs. lower $(\mathrm{n}=5, \mathrm{Q}=7.4$, $\mathrm{p}=0.116)$, and $\mathrm{RR}=1.93(1.50,2.49)$ for high levels of plasma Hcy(risk factor) vs. lower ( $\mathrm{n}=6$ data points; $\mathrm{Q}=2.64, \mathrm{p}=0.620)$. Given the observed prevalence of exposure from the largest study per risk factor included in each meta-analysis, the population attributable risk percent (PAR\%) with its 95\% CI was estimated as follows: for low education: $24.0 \%$ with a $95 \%$ CI: 8.4-39.6; for mid-life smoking it was $31.0 \%$ with a $95 \%$ CI: 17.9 44.3; for physical activity (lower vs. higher) it was 31.9\% with 95\% CI: 22.7-41.2; for high vs. low Hcy, it was $21.7 \%$ with a $95 \%$ CI: $12.8-30.6$; for lower vs. higher fish consumption (<weekly vs. $\geq$ weekly), it was $21.9 \%$ with 95\% CI:4.7-39.1. There was no significant publication bias, taking all selected risk factors for incident $\mathrm{AD}$ together. 
A large number of epidemiologic studies were initially conducted to examine the effects of socio-economic factors, mainly educational attainment, and were later used to assess the validity of alternative hypotheses regarding the presence of behavioral or health-related mediating factors. To this end, several behavioral and nutritional risk factors were studied in relation to various cognitive outcomes. For instance, it was hypothesized that low SES was associated with higher prevalence of smoking which in turn may affect cognitive performance and change over time. While few studies found weak or no association between smoking and cognitive decline, many others found a positive association whereby smoking increased the risk of decline. Alcohol was found in general to have a U-shaped association with the risk of decline, while caffeine was shown to increase perceptual speed and vigilance as well as memory and other more complex functions in at least two cohort studies and one cross-sectional study. Physical activity was shown to protect against cognitive decline as corroborated by a number of prospective cohort studies.

Among nutritional factors, dietary and supplemental antioxidants were shown in some studies to reduce the risk of cognitive decline while in others they showed no appreciable effect. Other micronutrients including B-Vitamins and folate were shown to be protective against cognitive decline, through their dampening effect on plasma Hcy which was shown to consistently increase the risk of dementia, particularly of the AD type. In addition, studies show that $n-3$ fatty acids with their antiinflammatory and cardio-protective properties can help reduce the risk of cognitive decline and impairment in some studies but not in others. Among nutritional factors, caffeine seems to be the factor hypothesized to have a protective effect with the smallest number of current studies.

\section{Conclusions}

In conclusion, the consistency of findings between studies varied for each selected risk or protective modifiable factors (highest consistency observed for physical activity). Secondly, a moderate to strong association was observed between some selected factors and incident AD (strongest for low education and elevated Hcy). Combining both criteria (strength of association in the case of incident $\mathrm{AD}$ and consistency overall), the strongest evidence thus far is an increased risk with elevated plasma Hcy levels or lower educational attainment and a lowered risk with increased physical activity. Nevertheless, more studies are needed to verify the consistency, particularly regarding caffeine. A comprehensive meta-analysis requires additional research for certain risk factors of incident $\mathrm{AD}$ or dementia. For incident $\mathrm{AD}$, selected risk factors may potentially account on average for $21.7 \%-31.9 \%$ of $\mathrm{AD}$ cases for each risk factor considered (with 95\% CI: 8.4\%-44.3\%) (highest for midlife smoking and physical activity), given the estimated prevalence of those factors from the largest available study. Thus, on average, one in five to one in three cases of $\mathrm{AD}$ can potentially be averted if those risk factors were eliminated from populations with comparable exposure prevalence.

\section{Additional file}

Additional file 1: Figure S1. Begg's funnel plot with pseudo 95\% confidence limits.

\section{Abbreviations}

AD: Alzheimer's disease; VaD: Vascular dementia; DLB: Dementia with Lewy bodies; PD-D: Parkinson's disease with dementia; MD: Mixed dementia; FTD: Fronot-parietal dementia; OD: Other dementia; MCl: Mild cognitive impairment; ADDTC: Alzheimer's disease diagnostic and treatment centers; DSM-IV: Diagnostic and statistical manual, $4^{\text {th }}$ edition; ICD-10: International classification of disease, $10^{\text {th }}$ edition; NINCDS-ADRDA: National Institute of neurological and communicative disorders and stroke - the Alzheimer's disease and related disorders association; NINDS-AIREN: National institute of neurological and communicative disorders and stroke-Association Internationale pour la Recherche et l'Enseignement en Neurosciences; ApoE: Apolipoprotein E; PAR\%: Population attributable risk percent; OR: Odd ratio; RR: Relative risk; HR: Hazard ratio; Cl: Confidence interval;

Prexp: Prevalence of each exposure; SE: Standard errors; SD: Standard deviation; Edu: Education; Smok: Smoking status; Alco: Alcohol consumption; PA: Physical activity; CAFF: Caffeine consumption; Antiox: Antioxidants; N-3 Fa: n-3 fatty acids; SES: Socio-economic status; SEP: Socio-economic position; Hcy: Homocysteine; EPA: Eicosapentanoic acid; DHA: Docosahexaenoic acid; DGLA: Dihomogaminalinolenic acid; GLA: Gamma-linoleic acid;

AA: Arachidonic acid; PUFA: Polyunsaturated fatty acid;

MUFA: monounsaturated fatty acid; MMSE: Mini-mental state examination; B: Both; M: Men; W: Women; UK: United Kingdom; US: United States.

\section{Competing interests}

The authors declare that they have no competing interests.

\section{Authors' contributions}

MAB: conceptualization, literature search and review, plan of analysis, data management, statistical analysis (including meta-analysis), writing of the manuscript, revision of the manuscript. HAB: Literature search and review, plan of analysis, writing of parts of the manuscript, revision of the manuscript. AG: Literature search and review, plan of analysis, writing of parts of the manuscript, revision of the manuscript. AT: Literature search and reivew, writing of parts of the manuscript, revision of the manuscript. ABZ: Plan of analysis, write-up of parts of the manuscript, revision of the manuscript. YW: Plan of analysis, write-up of parts of the manuscript, revision of the manuscript. All authors read and approved the final manuscript.

\section{Authors' information}

Youfa Wang and Alan B Zonderman are senior authors.

\section{Acknowledgments}

This study was supported by the Intramural Research Program of the National Institute on Aging, NIA/NIH/IRP. The authors would like to thank Mr. James Byrnes, NIA/NIH/IRP, for help with literature search and retrieval. Special thanks also go to Drs. Lori L. Beason-Held and Madhav Thambisetty, $\mathrm{NIA} / \mathrm{NIH} / \mathrm{IRP}$, for their review and comments on the manuscript.

\section{Author details}

${ }^{1}$ Laboratory of Epidemiology and Population Sciences, National Institute on Aging, NIA/NIH/IRP, 251 Bayview Blvd., Suite 100, Room \#: 04B118, Baltimore, MD 21224, USA. ${ }^{2}$ Graduate program in Public Health, Eastern Virginia Medical School, Norfolk, VA, UK. ${ }^{3}$ Department of Epidemiology and Environmental Health, School of Public Health and Health Professions, University at Buffalo, State University of New York, New York, USA. ${ }^{4}$ John Hopkins Global Center on Childhood Obesity, Where Systems Science Meets Public Health, 
Department of International Health, Johns Hopkins Bloomberg School of Public Health, Baltimore, MD, USA.

Received: 11 September 2013 Accepted: 13 May 2014 Published: 24 June 2014

\section{References}

1. de Champlain J, Wu R, Girouard H, Karas M, ELM A, Laplante MA, Wu L: Oxidative stress in hypertension. Clin Exp Hypertens 2004, 26:593-601.

2. Verhaeghen P, Salthouse TA: Meta-analyses of age-cognition relations in adulthood: estimates of linear and nonlinear age effects and structural models. Psychol Bull 1997, 122:231-249.

3. Moritz DJ, Kasl SV, Berkman LF: Cognitive functioning and the incidence of limitations in activities of daily living in an elderly community sample. Am J Epidemiol 1995, 141:41-49.

4. Lobo A, Launer LJ, Fratiglioni L, Andersen K, Di Carlo A, Breteler MM, Copeland JR, Dartigues JF, Jagger C, Martinez-Lage J, Soininen H, Hofman A: Prevalence of dementia and major subtypes in Europe: a collaborative study of population-based cohorts. Neurologic Diseases in the Elderly Research Group. Neurology 2000, 54:S4-9.

5. Li G, Shen YC, Chen CH, Zhao YW, Li SR, Lu M: An epidemiological survey of age-related dementia in an urban area of Beijing. Acta Psychiatr Scand 1989, 79:557-563.

6. Fichter MM, Meller I, Schroppel H, Steinkirchner R: Dementia and cognitive impairment in the oldest old in the community. Prevalence and comorbidity. Br J Psychiatry 1995, 166:621-629.

7. Ankri J, Poupard M: Prevalence and incidence of dementia among the very old. Review of the literature. Rev Epidemiol Sante Publique 2003, 51:349-360.

8. Jorm AF, Jolley D: The incidence of dementia: a meta-analysis. Neurology 1998, 51:728-733.

9. Ott A, Breteler MM, van Harskamp F, Claus JJ, van der Cammen TJ, Grobbee DE, Hofman A: Prevalence of Alzheimer's disease and vascular dementia: association with education. The Rotterdam study. BMJ 1995, 310:970-973.

10. Liu HC, Lin KN, Teng EL, Wang SJ, Fuh JL, Guo NW, Chou P, Hu HH, Chiang BN: Prevalence and subtypes of dementia in Taiwan: a community survey of 5297 individuals. J Am Geriatr Soc 1995, 43:144-149.

11. McKhann G, Drachman D, Folstein M, Katzman R, Price D, Stadlan EM: Clinical diagnosis of Alzheimer's disease: report of the NINCDS-ADRDA work group under the auspices of Department of health and human services task force on Alzheimer's disease. Neurology 1984, 34:939-944.

12. McKhann GM, Knopman DS, Chertkow H, Hyman BT, Jack CR Jr, Kawas CH, Klunk WE, Koroshetz WJ, Manly JJ, Mayeux R, Mohs RC, Morris JC, Rossor MN, Scheltens P, Carrillo MC, Thies B, Weintraub S, Phelps CH: The diagnosis of dementia due to Alzheimer's disease: recommendations from the National Institute on Aging-Alzheimer's association workgroups on diagnostic guidelines for Alzheimer's disease. Alzheimers Dement 2011, 7:263-269.

13. Roman GC, Tatemichi TK, Erkinjuntti T, Cummings JL, Masdeu JC, Garcia JH, Amaducci L, Orgogozo JM, Brun A, Hofman A, et al: Vascular dementia: diagnostic criteria for research studies. Report of the NINDS-AIREN international workshop. Neurology 1993, 43:250-260.

14. Hachinski VC, lliff LD, Zilhka E, Du Boulay GH, McAllister VL, Marshall J, Russell RW, Symon L: Cerebral blood flow in dementia. Arch Neurol 1975, 32:632-637.

15. The Lund and Manchester Groups: Clinical and neuropathological criteria for frontotemporal dementia. The Lund and Manchester groups. J Neurol Neurosurg Psychiatry 1994, 57:416-418

16. McKeith IG, Galasko D, Kosaka K, Perry EK, Dickson DW, Hansen LA, Salmon DP, Lowe J, Mirra SS, Byrne EJ, Lennox G, Quinn NP, Edwardson JA, Ince PG, Bergeron C, Burns A, Miller BL, Lovestone S, Collerton D, Jansen EN, Ballard C, de Vos RA, Wilcock GK, Jellinger KA, Perry RH: Consensus guidelines for the clinical and pathologic diagnosis of dementia with Lewy bodies (DLB): report of the consortium on DLB international workshop. Neurology 1996, 47:1113-1124.

17. Crecelius C: Diagnosis and treatment of non-Alzheimer's dementias. J Am Med Dir Assoc 2003, 4:H25-29.

18. Zekry D, Hauw JJ, Gold G: Mixed dementia: epidemiology, diagnosis, and treatment. J Am Geriatr Soc 2002, 50:1431-1438.

19. Gorelick PB, Scuteri A, Black SE, Decarli C, Greenberg SM, ladecola C, Launer L, Laurent S, Lopez OL, Nyenhuis D, Petersen RC, Schneider JA, Tzourio C, Arnett DK, Bennett DA, Chui HC, Higashida RT, Lindquist R, Nilsson PM, Roman GC, Sellke FW, Seshadri S, American Heart Association Stroke
Council, Council on Epidemiology and Prevention, Council on Cardiovascular Nursing, Council on Cardiovascular Radiology and Intervention, and Council on Cardiovascular Surgery and Anesthesia: Vascular contributions to cognitive impairment and dementia: a statement for healthcare professionals from the american heart association/american stroke association. Stroke 2011, 42:2672-2713.

20. Barnes DE, Yaffe K: The projected effect of risk factor reduction on Alzheimer's disease prevalence. Lancet Neurol 2011, 10:819-828.

21. Zhang MY, Katzman R, Salmon D, Jin H, Cai GJ, Wang ZY, Qu GY, Grant I, Yu $E$, Levy $P$, et al: The prevalence of dementia and Alzheimer's disease in Shanghai, China: impact of age, gender, and education. Ann Neurol 1990, 27:428-437.

22. Ogunniyi A, Lekwauwa UG, Osuntokun BO: Influence of education on aspects of cognitive functions in non-demented elderly Nigerians. Neuroepidemiology 1991, 10:246-250.

23. Dealberto MJ, Gagnon M, Barberger-Gateau P, Dartigues JF, Alperovitch A: [Influence of educational status on a screening test for dementia, the mini-mental state examination]. Rev Epidemio/ Sante Publique 1992, 40:93-101.

24. Koivisto K, Helkala EL, Reinikainen KJ, Hanninen T, Mykkanen L, Laakso M, Pyorala K, Riekkinen PJ: Population-based dementia screening program in Kuopio: the effect of education, age, and sex on brief neuropsychological tests. J Geriatr Psychiatry Neurol 1992, 5:162-171.

25. Evans DA, Beckett LA, Albert MS, Hebert LE, Scherr PA, Funkenstein HH, Taylor JO: Level of education and change in cognitive function in a community population of older persons. Ann Epidemiol 1993, 3:71-77.

26. Paykel ES, Brayne C, Huppert FA, Gill C, Barkley C, Gehlhaar E, Beardsall L, Girling DM, Pollitt P, O'Connor D: Incidence of dementia in a population older than 75 years in the United Kingdom. Arch Gen Psychiatry 1994, 51:325-332.

27. White L, Katzman R, Losonczy K, Salive M, Wallace R, Berkman L, Taylor J, Fillenbaum G, Havlik R: Association of education with incidence of cognitive impairment in three established populations for epidemiologic studies of the elderly. J Clin Epidemiol 1994, 47:363-374.

28. Cobb JL, Wolf PA, Au R, White R, D'Agostino RB: The effect of education on the incidence of dementia and Alzheimer's disease in the Framingham Study. Neurology 1995, 45:1707-1712.

29. Farmer ME, Kittner SJ, Rae DS, Bartko JJ, Regier DA: Education and change in cognitive function. The epidemiologic catchment area study. Ann Epidemiol 1995, 5:1-7.

30. Callahan CM, Hall KS, Hui SL, Musick BS, Unverzagt FW, Hendrie HC: Relationship of age, education, and occupation with dementia among a community-based sample of African Americans. Arch Neurol 1996, 53:134-140.

31. Hanninen T, Koivisto K, Reinikainen KJ, Helkala EL, Soininen H, Mykkanen L, Laakso M, Riekkinen PJ: Prevalence of ageing-associated cognitive decline in an elderly population. Age Ageing 1996, 25:201-205

32. Christensen $\mathrm{H}$, Korten $\mathrm{AE}$, Jorm AF, Henderson AS, Jacomb PA, Rodgers $B$, Mackinnon AJ: Education and decline in cognitive performance: compensatory but not protective. Int J Geriatr Psychiatry 1997, 12:323-330.

33. Evans DA, Hebert LE, Beckett LA, Scherr PA, Albert MS, Chown MJ, Pilgrim DM, Taylor JO: Education and other measures of socioeconomic status and risk of incident Alzheimer disease in a defined population of older persons. Arch Neurol 1997, 54:1399-1405.

34. Freidl W, Schmidt R, Stronegger WJ, Reinhart B: The impact of sociodemographic, environmental, and behavioral factors, and cerebrovascular risk factors as potential predictors of the mattis dementia rating scale. J Gerontol A Biol Sci Med Sci 1997, 52:M111-116.

35. Kalmijn S, Feskens EJ, Launer $\amalg$, Kromhout D: Longitudinal study of the effect of apolipoprotein e4 allele on the association between education and cognitive decline in elderly men. BMJ 1997, 314:34-35.

36. Kilander L, Nyman $H$, Boberg M, Lithell $H$ : Cognitive function, vascular risk factors and education. A cross-sectional study based on a cohort of 70 year-old men. J Intern Med 1997, 242:313-321

37. Schmand B, Smit J, Lindeboom J, Smits C, Hooijer C, Jonker C, Deelman B: Low education is a genuine risk factor for accelerated memory decline and dementia. J Clin Epidemiol 1997, 50:1025-1033.

38. Schmand B, Smit JH, Geerlings MI, Lindeboom J: The effects of intelligence and education on the development of dementia. A test of the brain reserve hypothesis. Psychol Med 1997, 27:1337-1344.

39. Cerhan JR, Folsom AR, Mortimer JA, Shahar E, Knopman DS, McGovern PG, Hays MA, Crum LD, Heiss G: Correlates of cognitive function in middle-aged 
adults. Atherosclerosis risk in communities (ARIC) study investigators. Gerontology 1998, 44:95-105.

40. De Ronchi D, Fratiglioni L, Rucci P, Paternico A, Graziani S, Dalmonte E: The effect of education on dementia occurrence in an Italian population with middle to high socioeconomic status. Neurology 1998, 50:1231-1238.

41. Lin RT, Lai CL, Tai CT, Liu CK, Yen YY, Howng SL: Prevalence and subtypes of dementia in southern Taiwan: impact of age, sex, education, and urbanization. J Neurol Sci 1998, 160:67-75.

42. Lyketsos CG, Chen LS, Anthony JC: Cognitive decline in adulthood: an 11.5-year follow-up of the Baltimore epidemiologic catchment area study. Am J Psychiatry 1999, 156:58-65.

43. Letenneur L, Gilleron V, Commenges D, Helmer C, Orgogozo JM, Dartigues JF: Are sex and educational level independent predictors of dementia and Alzheimer's disease? Incidence data from the PAQUID project. J Neurol Neurosurg Psychiatry 1999, 66:177-183.

44. Ott A, van Rossum CT, van Harskamp F, van de Mheen H, Hofman A, Breteler MM: Education and the incidence of dementia in a large population-based study: the Rotterdam study. Neurology 1999, 52:663-666.

45. Aevarsson O, Skoog I: A longitudinal population study of the mini-mental state examination in the very old: relation to dementia and education. Dement Geriatr Cogn Disord 2000, 11:166-175.

46. Qiu C, Backman L, Winblad B, Aguero-Torres H, Fratiglioni L: The influence of education on clinically diagnosed dementia incidence and mortality data from the Kungsholmen project. Arch Neurol 2001, 58:2034-2039.

47. Alvarado BE, Zunzunegui MV, Del Ser T, Beland F: Cognitive decline is related to education and occupation in a Spanish elderly cohort. Aging Clin Exp Res 2002, 14:132-142.

48. Cagney KA, Lauderdale DS: Education, wealth, and cognitive function in later life. J Gerontol B Psychol Sci Soc Sci 2002, 57:P163-172

49. Herrera E Jr, Caramelli P, Silveira AS, Nitrini R: Epidemiologic survey of dementia in a community-dwelling Brazilian population. Alzheimer Dis Assoc Disord 2002, 16:103-108.

50. Ravaglia G, Forti P, Maioli F, Sacchetti L, Mariani E, Nativio V, Talerico T, Vettori C, Macini PL: Education, occupation, and prevalence of dementia: findings from the Conselice study. Dement Geriatr Cogn Disord 2002, 14:90-100.

51. Wight RG, Aneshensel CS, Seeman TE: Educational attainment, continued learning experience, and cognitive function among older men. J Aging Health 2002, 14:211-236.

52. Lee S, Kawachi I, Berkman LF, Grodstein F: Education, other socioeconomic indicators, and cognitive function. Am J Epidemiol 2003, 157:712-720.

53. Seeman TE, Huang MH, Bretsky P, Crimmins E, Launer L, Guralnik JM: Education and APOE-e4 in longitudinal cognitive decline: MacArthur studies of successful aging. J Gerontol B Psychol Sci Soc Sci 2005, 60:P74-83.

54. Lee S, Buring JE, Cook NR, Grodstein F: The relation of education and income to cognitive function among professional women. Neuroepidemiology 2006, 26:93-101.

55. Shadlen MF, Siscovick D, Fitzpatrick AL, Dulberg C, Kuller LH, Jackson S: Education, cognitive test scores, and black-white differences in dementia risk. J Am Geriatr Soc 2006, 54:898-905.

56. Zhang ZX, Zahner GE, Román GC, Liu XH, Wu CB, Hong Z, Hong X, Tang MN, Zhou B, Qu QM, Zhang XJ, Li H: Socio-demographic variation of dementia subtypes in china: methodology and results of a prevalence study in Beijing, Chengdu, Shanghai, and Xian. Neuroepidemiology 2006, 27:177-187.

57. Zhou DF, Wu CS, Qi H, Fan JH, Sun XD, Como P, Qiao YL, Zhang L, Kieburtz K: Prevalence of dementia in rural China: impact of age, gender and education. Acta Neurol Scand 2006, 114:273-280.

58. Galasko D, Salmon D, Gamst A, Olichney J, Thal LJ, Silbert L, Kaye J, Brooks $P$, Adonay R, Craig UK, Schellenberg G, Borenstein AR: Prevalence of dementia in Chamorros on Guam: relationship to age, gender, education, and APOE. Neurology 2007, 68:1772-1781.

59. van Hooren SA, Valentijn AM, Bosma H, Ponds RW, van Boxtel MP, Jolles J: Cognitive functioning in healthy older adults aged 64-81: a cohort study into the effects of age, sex, and education. Neuropsychol Dev Cogn $B$ Aging Neuropsychol Cogn 2007, 14:40-54.

60. Christensen H, Batterham PJ, Mackinnon AJ, Anstey KJ, Wen W, Sachdev PS: Education, atrophy, and cognitive change in an epidemiological sample in early old age. Am J Geriatr Psychiatry 2009, 17:218-226.

61. Dotson VM, Kitner-Triolo MH, Evans MK, Zonderman AB: Effects of race and socioeconomic status on the relative influence of education and literacy on cognitive functioning. J Int Neuropsychol Soc 2009, 15:580-589.
62. Gavrila D, Antunez C, Tormo MJ, Carles R, Garcia Santos JM, Parrilla G, Fortuna L, Jimenez J, Salmeron D, Navarro C: Prevalence of dementia and cognitive impairment in Southeastern Spain: the Ariadna study. Acta Neurol Scand 2009, 120:300-307.

63. Peters R, Beckett N, Geneva M, Tzekova M, Lu FH, Poulter R, Gainsborough N, Williams B, de Vernejoul MC, Fletcher A, Bulpitt C: Sociodemographic and lifestyle risk factors for incident dementia and cognitive decline in the HYVET. Age Ageing 2009, 38:521-527.

64. Wilson RS, Hebert LE, Scherr PA, Barnes LL, de Leon CF M, Evans DA: Educational attainment and cognitive decline in old age. Neurology 2009, 72:460-465

65. Hamid TA, Krishnaswamy S, Abdullah SS, Momtaz YA: Sociodemographic risk factors and correlates of dementia in older Malaysians. Dement Geriatr Cogn Disord 2010, 30:533-539.

66. Mathuranath PS, Cherian PJ, Mathew R, Kumar S, George A, Alexander A Ranjith N, Sarma PS: Dementia in Kerala, South India: prevalence and influence of age, education and gender. Int J Geriatr Psychiatry 2010, 25:290-297

67. Scazufca M, Almeida OP, Menezes PR: The role of literacy, occupation and income in dementia prevention: the Sao Paulo ageing \& health study (SPAH). Int Psychogeriatr 2010, 22:1209-1215.

68. Castro-Costa E, Dewey ME, Uchoa E, Firmo JO, Lima-Costa MF, Stewart R: Trajectories of cognitive decline over 10 years in a Brazilian elderly population: the Bambui cohort study of aging. Cad Saude Publica 2011, 27(Suppl 3):S345-350.

69. Marengoni A, Fratiglioni L, Bandinelli S, Ferrucci L: Socioeconomic status during lifetime and cognitive impairment no-dementia in late life: the population-based aging in the Chianti area (InCHIANTI) study. J Alzheimers Dis 2011, 24:559-568.

70. Mejia-Arango S, Gutierrez LM: Prevalence and incidence rates of dementia and cognitive impairment no dementia in the Mexican population: data from the Mexican health and aging study. J Aging Health 2011, 23:1050-1074

71. Zahodne LB, Glymour MM, Sparks C, Bontempo D, Dixon RA, MacDonald SW, Manly JJ: Education does not slow cognitive decline with aging: 12-year evidence from the victoria longitudinal study. J Int Neuropsychol Soc 2011, 17:1039-1046.

72. Herbert LE, Scherr PA, Beckett LA, Albert MS, Rosner B, Taylor JO, Evans DA Relation of smoking and low-to-moderate alcohol consumption to change in cognitive function: a longitudinal study in a defined community of older persons. Am J Epidemiol 1993, 137:881-891.

73. Letenneur L, Dartigues JF, Commenges D, Barberger-Gateau P, Tessier JF, Orgogozo JM: Tobacco consumption and cognitive impairment in elderly people. A population-based study. Ann Epidemio/ 1994, 4:449-454.

74. Ford AB, Mefrouche Z, Friedland RP, Debanne SM: Smoking and cognitive impairment: a population-based study. J Am Geriatr Soc 1996, 44:905-909.

75. Galanis DJ, Petrovitch H, Launer LJ, Harris TB, Foley DJ, White LR: Smoking history in middle age and subsequent cognitive performance in elderly Japanese-American men. The Honolulu-Asia Aging Study. Am J Epidemio/ 1997, 145:507-515

76. Broe GA, Creasey H, Jorm AF, Bennett HP, Casey B, Waite LM, Grayson DA, Cullen J: Health habits and risk of cognitive impairment and dementia in old age: a prospective study on the effects of exercise, smoking and alcohol consumption. Aust N Z J Public Health 1998, 22:621-623.

77. Edelstein SL, Kritz-Silverstein D, Barrett-Connor E: Prospective association of smoking and alcohol use with cognitive function in an elderly cohort. J Womens Health 1998, 7:1271-1281.

78. Ott A, Slooter AJ, Hofman A, van Harskamp F, Witteman JC, Van Broeckhoven C, van Duijn CM, Breteler MM: Smoking and risk of dementia and Alzheimer's disease in a population-based cohort study: the Rotterdam study. Lancet 1998, 351:1840-1843

79. Carmelli D, Swan GE, Reed T, Schellenberg GD, Christian JC: The effect of apolipoprotein E epsilon4 in the relationships of smoking and drinking to cognitive function. Neuroepidemiology 1999, 18:125-133.

80. Elwood PC, Gallacher JE, Hopkinson CA, Pickering J, Rabbitt P, Stollery B, Brayne C, Huppert FA, Bayer A: Smoking, drinking, and other life style factors and cognitive function in men in the Caerphilly cohort. J Epidemiol Community Health 1999, 53:9-14.

81. Cervilla JA, Prince M, Mann A: Smoking, drinking, and incident cognitive impairment: a cohort community based study included in the Gospel Oak project. J Neurol Neurosurg Psychiatry 2000, 68:622-626. 
82. Doll R, Peto R, Boreham J, Sutherland I: Smoking and dementia in male British doctors: prospective study. BMJ 2000, 320:1097-1102.

83. Kalmijn S, van Boxtel MP, Verschuren MW, Jolles J, Launer LJ: Cigarette smoking and alcohol consumption in relation to cognitive performance in middle age. Am J Epidemio/ 2002, 156:936-944.

84. Chen WT, Wang PN, Wang SJ, Fuh JL, Lin KN, Liu HC: Smoking and cognitive performance in the community elderly: a longitudinal study. J Geriatr Psychiatry Neurol 2003, 16:18-22.

85. Richards M, Jarvis MJ, Thompson N, Wadsworth ME: Cigarette smoking and cognitive decline in midlife: evidence from a prospective birth cohort study. Am J Public Health 2003, 93:994-998.

86. Tyas SL, White LR, Petrovitch H, Webster Ross G, Foley DJ, Heimovitz HK, Launer LJ: Mid-life smoking and late-life dementia: the Honolulu-Asia aging study. Neurobiol Aging 2003, 24:589-596.

87. Zhou H, Deng J, Li J, Wang Y, Zhang M, He H: Study of the relationship between cigarette smoking, alcohol drinking and cognitive impairment among elderly people in China. Age Ageing 2003, 32:205-210.

88. Juan D, Zhou DH, Li J, Wang JY, Gao C, Chen M: A 2-year follow-up study of cigarette smoking and risk of dementia. Eur J Neurol 2004, 11:277-282.

89. Ott A, Andersen K, Dewey ME, Letenneur L, Brayne C, Copeland JR, Dartigues JF, Kragh-Sorensen P, Lobo A, Martinez-Lage JM, Stijnen T, Hofman A, Launer $\sqcup$, EURODEM Incidence Research Group: Effect of smoking on global cognitive function in nondemented elderly. Neurology 2004, 62:920-924.

90. Solfrizzi V, Panza F, Colacicco AM, D'Introno A, Capurso C, Torres F, Grigoletto F, Maggi S, Del Parigi A, Reiman EM, Caselli RJ, Scafato E, Farchi G, Capurso A, Italian Longitudinal Study on Aging Working Group: Vascular risk factors, incidence of $\mathrm{MCl}$, and rates of progression to dementia. Neurology 2004, 63:1882-1891.

91. Aleman A, Muller M, de Haan EH, van der Schouw YT: Vascular risk factors and cognitive function in a sample of independently living men. Neurobiol Aging 2005, 26:485-490

92. Reitz C, Luchsinger J, Tang MX, Mayeux R: Effect of smoking and time on cognitive function in the elderly without dementia. Neurology 2005, 65:870-875.

93. Whitmer RA, Sidney S, Selby J, Johnston SC, Yaffe K: Midlife cardiovascular risk factors and risk of dementia in late life. Neurology 2005, 64:277-281.

94. Stewart MC, Deary IJ, Fowkes FG, Price JF: Relationship between lifetime smoking, smoking status at older age and human cognitive function. Neuroepidemiology 2006, 26:83-92.

95. Reitz C, den Heijer T, van Duijn C, Hofman A, Breteler MM: Relation between smoking and risk of dementia and Alzheimer disease: the Rotterdam study. Neurology 2007, 69:998-1005.

96. Nooyens AC, van Gelder BM, Verschuren WM: Smoking and cognitive decline among middle-aged men and women: the Doetinchem cohort study. Am J Public Health 2008, 98:2244-2250.

97. Sabia S, Marmot M, Dufouil C, Singh-Manoux A: Smoking history and cognitive function in middle age from the Whitehall II study. Arch Intern Med 2008, 168:1165-1173.

98. Alonso A, Mosley TH Jr, Gottesman RF, Catellier D, Sharrett AR, Coresh J: Risk of dementia hospitalisation associated with cardiovascular risk factors in midlife and older age: the Atherosclerosis risk in communities (ARIC) study. J Neurol Neurosurg Psychiatry 2009, 80:1194-1201.

99. Collins N, Sachs-Ericsson N, Preacher KJ, Sheffield KM, Markides K: Smoking increases risk for cognitive decline among community-dwelling older Mexican Americans. Am J Geriatr Psychiatry 2009, 17:934-942.

100. Huang CQ, Dong BR, Zhang YL, Wu HM, Liu QX: Association of cognitive impairment with smoking, alcohol consumption, tea consumption, and exercise among Chinese nonagenarians/centenarians. Cogn Behav Neurol 2009, 22:190-196.

101. Rusanen M, Rovio S, Ngandu T, Nissinen A, Tuomilehto J, Soininen H, Kivipelto M: Midlife smoking, apolipoprotein $\mathrm{E}$ and risk of dementia and Alzheimer's disease: a population-based cardiovascular risk factors, aging and dementia study. Dement Geriatr Cogn Disord 2010, 30:277-284.

102. Wang CC, Lu TH, Liao WC, Yuan SC, Kuo PC, Chuang HL, Lee MC, Yen CH: Cigarette smoking and cognitive impairment: a 10-year cohort study in Taiwan. Arch Gerontol Geriatr 2010, 51:143-148.

103. Ronnemaa E, Zethelius B, Lannfelt L, Kilander L: Vascular risk factors and dementia: 40-year follow-up of a population-based cohort. Dement Geriatr Cogn Disord 2011, 31:460-466.

104. Rusanen M, Kivipelto M, Quesenberry CP Jr, Zhou J, Whitmer RA: Heavy smoking in midlife and long-term risk of Alzheimer disease and vascular dementia. Arch Intern Med 2011, 171:333-339.
105. Sabia S, Elbaz A, Dugravot A, Head J, Shipley M, Hagger-Johnson G, Kivimaki $M$, Singh-Manoux A: Impact of smoking on cognitive decline in early old age: the Whitehall II cohort study. Arch Gen Psychiatry 2012, 69:627-635.

106. Hendrie HC, Gao S, Hall KS, Hui SL, Unverzagt FW: The relationship between alcohol consumption, cognitive performance, and daily functioning in an urban sample of older black Americans. J Am Geriatr Soc 1996, 44:1158-1165.

107. Dufouil C, Ducimetiere $P$, Alperovitch A: Sex differences in the association between alcohol consumption and cognitive performance. EVA study group. Epidemiology of vascular aging. Am J Epidemiol 1997, 146:405-412.

108. Elias PK, Elias MF, D'Agostino RB, Silbershatz H, Wolf PA: Alcohol consumption and cognitive performance in the Framingham heart study. Am J Epidemio/ 1999, 150:580-589.

109. Bond GE, Burr R, McCurry SM, Graves AB, Larson EB: Alcohol, aging, and cognitive performance in a cohort of Japanese Americans aged 65 and older: the Kame project. Int Psychogeriatr 2001, 13:207-223.

110. Zuccala G, Onder G, Pedone C, Cesari M, Landi F, Bernabei R, Cocchi A: Dose-related impact of alcohol consumption on cognitive function in advanced age: results of a multicenter survey. Alcohol Clin Exp Res 2001, 25:1743-1748

111. Leroi I, Sheppard JM, Lyketsos CG: Cognitive function after 11.5 years of alcohol use: relation to alcohol use. Am J Epidemiol 2002, 156:747-752

112. Krahn D, Freese J, Hauser R, Barry K, Goodman B: Alcohol use and cognition at mid-life: the importance of adjusting for baseline cognitive ability and educational attainment. Alcohol Clin Exp Res 2003, 27:1162-1166

113. Anttila T, Helkala EL, Viitanen M, Kareholt I, Fratiglioni L, Winblad B, Soininen $\mathrm{H}$, Tuomilehto J, Nissinen A, Kivipelto M: Alcohol drinking in middle age and subsequent risk of mild cognitive impairment and dementia in old age: a prospective population based study. BMJ 2004, 329:539.

114. Bond GE, Burr R, McCurry SM, Rice MM, Borenstein AR, Kukull WA, Teri L, Bowen JD, McCormick WC, Larson EB: Alcohol, gender, and cognitive performance: a longitudinal study comparing older Japanese and non-Hispanic white Americans. J Aging Health 2004, 16:615-640.

115. Britton A, Singh-Manoux A, Marmot M: Alcohol consumption and cognitive function in the Whitehall II study. Am J Epidemiol 2004, 160:240-247.

116. Bond GE, Burr RL, McCurry SM, Rice MM, Borenstein AR, Larson EB: Alcohol and cognitive performance: a longitudinal study of older Japanese Americans. The Kame project. Int Psychogeriatr 2005, 17:653-668.

117. Ganguli M, Vander Bilt J, Saxton JA, Shen C, Dodge HH: Alcohol consumption and cognitive function in late life: a longitudinal community study. Neurology 2005, 65:1210-1217.

118. Richards M, Hardy R, Wadsworth ME: Alcohol consumption and midlife cognitive change in the British 1946 birth cohort study. Alcohol Alcohol 2005, 40:112-117.

119. Rodgers B, Windsor TD, Anstey KJ, Dear KB, FJ A, Christensen H: Non-linear relationships between cognitive function and alcohol consumption in young, middle-aged and older adults: the PATH through life project. Addiction 2005, 100:1280-1290.

120. Stampfer MJ, Kang JH, Chen J, Cherry R, Grodstein F: Effects of moderate alcohol consumption on cognitive function in women. $N$ Engl J Med 2005, 352:245-253.

121. Reid MC, Van Ness PH, Hawkins KA, Towle V, Concato J, Guo Z: Light to moderate alcohol consumption is associated with better cognitive function among older male veterans receiving primary care. J Geriatr Psychiatry Neurol 2006, 19:98-105

122. Wright CB, Elkind MS, Luo X, Paik MC, Sacco RL: Reported alcohol consumption and cognitive decline: the northern Manhattan study. Neuroepidemiology 2006, 27:201-207.

123. Ngandu T, Helkala EL, Soininen H, Winblad B, Tuomilehto J, Nissinen A, Kivipelto M: Alcohol drinking and cognitive functions: findings from the cardiovascular risk factors aging and dementia (CAIDE) study. Dement Geriatr Cogn Disord 2007, 23:140-149.

124. Solfrizzi V, D'Introno A, Colacicco AM, Capurso C, Del Parigi A, Baldassarre G, Scapicchio P, Scafato E, Amodio M, Capurso A, Panza F: Alcohol consumption, mild cognitive impairment, and progression to dementia. Neurology 2007, 68:1790-1799.

125. Xu G, Liu X, Yin Q, Zhu W, Zhang R, Fan X: Alcohol consumption and transition of mild cognitive impairment to dementia. Psychiatry Clin Neurosci 2009, 63:43-49. 
126. Au Yeung SL, Jiang C, Zhang W, Lam TH, Cheng KK, Leung GM, Schooling CM: Moderate alcohol use and cognitive function in the Guangzhou Biobank cohort study. Ann Epidemiol 2010, 20:873-882

127. Chan KK, Chiu KC, Chu LW: Association between alcohol consumption and cognitive impairment in Southern Chinese older adults. Int J Geriatr Psychiatry 2010, 25:1272-1279.

128. Corley J, Jia X, Brett CE, Gow AJ, Starr JM, Kyle JA, McNeill G, Deary IJ: Alcohol intake and cognitive abilities in old age: the Lothian birth cohort 1936 study. Neuropsychology 2011, 25:166-175.

129. Gross AL, Rebok GW, Ford DE, Chu AY, Gallo JJ, Liang KY, Meoni LA, Shihab HM, Wang NY, Klag MJ: Alcohol consumption and domain-specific cognitive function in older adults: longitudinal data from the Johns Hopkins precursors study. J Gerontol B Psychol Sci Soc Sci 2011, 66:39-47.

130. Sabia S, Gueguen A, Berr C, Berkman L, Ankri J, Goldberg M, Zins M, Singh-Manoux A: High alcohol consumption in middle-aged adults is associated with poorer cognitive performance only in the low socio-economic group. Results from the GAZEL cohort study. Addiction 2011, 106:93-101.

131. Zanjani F, Downer BG, Kruger TM, Willis SL, Schaie KW: Alcohol effects on cognitive change in middle-aged and older adults. Aging Ment Health 2013, 17(1):12-23.

132. Ho SC, Woo J, Sham A, Chan SG, Yu AL: A 3-year follow-up study of social, lifestyle and health predictors of cognitive impairment in a Chinese older cohort. Int J Epidemiol 2001, 30:1389-1396.

133. Laurin D, Verreault R, Lindsay J, MacPherson K, Rockwood K: Physical activity and risk of cognitive impairment and dementia in elderly persons. Arch Neurol 2001, 58:498-504.

134. Schuit AJ, Feskens EJ, Launer LJ, Kromhout D: Physical activity and cognitive decline, the role of the apolipoprotein e4 allele. Med Sci Sports Exerc 2001, 33:772-777.

135. Yaffe $K$, Barnes D, Nevitt M, Lui LY, Covinsky K: A prospective study of physical activity and cognitive decline in elderly women: women who walk. Arch Intern Med 2001, 161:1703-1708.

136. Verghese J, Lipton RB, Katz MJ, Hall CB, Derby CA, Kuslansky G, Ambrose AF, Sliwinski M, Buschke $H$ : Leisure activities and the risk of dementia in the elderly. N Engl J Med 2003, 348:2508-2516.

137. Abbott RD, White LR, Ross GW, Masaki KH, Curb JD, Petrovitch H: Walking and dementia in physically capable elderly men. JAMA 2004, 292:1447-1453.

138. Lytle ME, Vander Bilt J, Pandav RS, Dodge HH, Ganguli M: Exercise level and cognitive decline: the MoVIES project. Alzheimer Dis Assoc Disord 2004, 18:57-64.

139. van Gelder BM, Tijhuis MA, Kalmijn S, Giampaoli S, Nissinen A, Kromhout D: Physical activity in relation to cognitive decline in elderly men: the FINE Study. Neurology 2004, 63:2316-2321

140. Weuve J, Kang JH, Manson JE, Breteler MM, Ware JH, Grodstein F: Physical activity, including walking, and cognitive function in older women. JAMA 2004, 292:1454-1461

141. Podewils LJ, Guallar E, Kuller LH, Fried LP, Lopez OL, Carlson M, Lyketsos CG: Physical activity, APOE genotype, and dementia risk: findings from the cardiovascular health cognition study. Am J Epidemiol 2005, 161:639-651.

142. Rovio S, Kareholt I, Helkala EL, Viitanen M, Winblad B, Tuomilehto J, Soininen $H$, Nissinen A, Kivipelto M: Leisure-time physical activity at midlife and the risk of dementia and Alzheimer's disease. Lancet Neurol 2005, 4:705-711.

143. Sturman MT, Morris MC, de Leon CF M, Bienias JL, Wilson RS, Evans DA: Physical activity, cognitive activity, and cognitive decline in a biracial community population. Arch Neurol 2005, 62:1750-1754.

144. Karp A, Paillard-Borg S, Wang HX, Silverstein M, Winblad B, Fratiglioni L: Mental, physical and social components in leisure activities equally contribute to decrease dementia risk. Dement Geriatr Cogn Disord 2006, 21:65-73.

145. Larson EB, Wang L, Bowen JD, McCormick WC, Teri L, Crane P, Kukull W: Exercise is associated with reduced risk for incident dementia among persons 65 years of age and older. Ann Intern Med 2006, 144:73-81.

146. Landi F, Russo A, Barillaro C, Cesari M, Pahor M, Danese P, Bernabei R, Onder G: Physical activity and risk of cognitive impairment among older persons living in the community. Aging Clin Exp Res 2007, 19:410-416.

147. Psaltopoulou T, Kyrozis A, Stathopoulos P, Trichopoulos D, Vassilopoulos D Trichopoulou A: Diet, physical activity and cognitive impairment among elders: the EPIC-Greece cohort (European Prospective Investigation into Cancer and Nutrition). Public Health Nutr 2008, 11:1054-1062.

148. Taaffe DR, Irie F, Masaki KH, Abbott RD, Petrovitch $H$, Ross GW, White LR: Physical activity, physical function, and incident dementia in elderly men: the Honolulu-Asia aging study. J Gerontol A Biol Sci Med Sci 2008, 63:529-535.

149. Gallucci M, Antuono P, Ongaro F, Forloni PL, Albani D, Amici GP, Regini C: Physical activity, socialization and reading in the elderly over the age of seventy: what is the relation with cognitive decline? Evidence from "The Treviso Longeva (TRELONG) study". Arch Gerontol Geriatr 2009, 48:284-286.

150. Scarmeas N, Luchsinger JA, Schupf N, Brickman AM, Cosentino S, Tang MX, Stern Y: Physical activity, diet, and risk of Alzheimer disease. JAMA 2009, 302:627-637.

151. Yaffe K, Fiocco AJ, Lindquist K, Vittinghoff E, Simonsick EM, Newman AB, Satterfield S, Rosano C, Rubin SM, Ayonayon HN, Harris TB: Predictors of maintaining cognitive function in older adults: the Health $A B C$ study. Neurology 2009, 72:2029-2035.

152. Chang M, Jonsson PV, Snaedal J, Bjornsson S, Saczynski JS, Aspelund T, Eiriksdottir G, Jonsdottir MK, Lopez OL, Harris TB, Gudnason V, Launer L: The effect of midlife physical activity on cognitive function among older adults: AGES-Reykjavik study. J Gerontol A Biol Sci Med Sci 2010, 65:1369-1374

153. Etgen T, Sander D, Huntgeburth U, Poppert H, Forstl H, Bickel H: Physical activity and incident cognitive impairment in elderly persons: the INVADE study. Arch Intern Med 2010, 170:186-193.

154. Gillum RF, Obisesan TO: Physical activity, cognitive function, and mortality in a US national cohort. Ann Epidemiol 2010, 20:251-257.

155. Middleton LE, Barnes DE, Lui LY, Yaffe K: Physical activity over the life course and its association with cognitive performance and impairment in old age. J Am Geriatr Soc 2010, 58:1322-1326.

156. Buchman AS, Boyle PA, Yu L, Shah RC, Wilson RS, Bennett DA: Total daily physical activity and the risk of $A D$ and cognitive decline in older adults. Neurology 2012, 78:1323-1329.

157. Lin F, Friedman E, Quinn J, Chen DG, Mapstone M: Effect of leisure activities on inflammation and cognitive function in an aging sample. Arch Gerontol Geriatr 2012, 54:e398-404.

158. Norton MC, Dew J, Smith H, Fauth E, Piercy KW, Breitner JC, Tschanz J, Wengreen $\mathrm{H}$, Welsh-Bohmer K: Lifestyle behavior pattern is associated with different levels of risk for incident dementia and Alzheimer's disease: the Cache county study. J Am Geriatr Soc 2012, 60:405-412.

159. Jarvis MJ: Does caffeine intake enhance absolute levels of cognitive performance? Psychopharmacology (Berl) 1993, 110:45-52.

160. Johnson-Kozlow M, Kritz-Silverstein D, Barrett-Connor E, Morton D: Coffee consumption and cognitive function among older adults. Am J Epidemiol 2002, 156:842-850.

161. van Boxtel MP, Schmitt JA, Bosma H, Jolles J: The effects of habitual caffeine use on cognitive change: a longitudinal perspective. Pharmacol Biochem Behav 2003, 75:921-927.

162. Kuriyama S, Hozawa A, Ohmori K, Shimazu T, Matsui T, Ebihara S, Awata S, Nagatomi R, Arai H, Tsuji I: Green tea consumption and cognitive function: a cross-sectional study from the Tsurugaya Project 1. Am J Clin Nutr 2006, 83:355-361.

163. van Gelder BM, Buijsse B, Tijhuis M, Kalmijn S, Giampaoli S, Nissinen A, Kromhout $D$ : Coffee consumption is inversely associated with cognitive decline in elderly European men: the FINE Study. Eur J Clin Nutr 2007, 61:226-232.

164. Ng TP, Feng L, Niti M, Kua EH, Yap KB: Tea consumption and cognitive impairment and decline in older Chinese adults. Am J Clin Nutr 2008, 88:224-231.

165. Eskelinen MH, Ngandu T, Tuomilehto J, Soininen $H$, Kivipelto M: Midlife coffee and tea drinking and the risk of late-life dementia: a populationbased CAIDE study. J Alzheimers Dis 2009, 16:85-91.

166. Laitala VS, Kaprio J, Koskenvuo M, Raiha I, Rinne JO, Silventoinen K: Coffee drinking in middle age is not associated with cognitive performance in old age. Am J Clin Nutr 2009, 90:640-646.

167. Nurk E, Refsum H, Drevon CA, Tell GS, Nygaard HA, Engedal K, Smith AD: Intake of flavonoid-rich wine, tea, and chocolate by elderly men and women is associated with better cognitive test performance. J Nutr 2009, 139:120-127.

168. Smith AP: Caffeine, cognitive failures and health in a non-working community sample. Hum Psychopharmacol 2009, 24:29-34.

169. Corley J, Jia X, Kyle JA, Gow AJ, Brett CE, Starr JM, McNeill G, Deary IJ: Caffeine consumption and cognitive function at age 70: the Lothian birth cohort 1936 study. Psychosom Med 2010, 72:206-214.

170. Feng L, Gwee X, Kua EH, Ng TP: Cognitive function and tea consumption in community dwelling older Chinese in Singapore. J Nutr Health Aging 2010, 14:433-438. 
171. Ritchie K, Artero S, Portet F, Brickman A, Muraskin J, Beanino E, Ancelin ML, Carriere I: Caffeine, cognitive functioning, and white matter lesions in the elderly: establishing causality from epidemiological evidence. J Alzheimers Dis 2010, 20(Suppl 1):S161-166.

172. Santos C, Lunet N, Azevedo A, de Mendonca A, Ritchie K, Barros H: Caffeine intake is associated with a lower risk of cognitive decline: a cohort study from Portugal. J Alzheimers Dis 2010, 20(Suppl 1):S175-185.

173. Arab L, Biggs ML, O'Meara ES, Longstreth WT, Crane PK, Fitzpatrick AL: Gender differences in tea, coffee, and cognitive decline in the elderly: the cardiovascular health study. J Alzheimers Dis 2011, 27:553-566.

174. Gelber RP, Petrovitch H, Masaki KH, Ross GW, White LR: Coffee intake in midlife and risk of dementia and its neuropathologic correlates. J Alzheimers Dis 2011, 23:607-615.

175. Feng L, Li J, Ng TP, Lee TS, Kua EH, Zeng Y: Tea drinking and cognitive function in oldest-old chinese. J Nutr Health Aging 2012, 16:754-758.

176. Jama JW, Launer LJ, Witteman JC, den Breeijen JH, Breteler MM, Grobbee $D E$, Hofman A: Dietary antioxidants and cognitive function in a population-based sample of older persons. The Rotterdam Study. Am J Epidemiol 1996, 144:275-280.

177. Mendelsohn AB, Belle SH, Stoehr GP, Ganguli M: Use of antioxidant supplements and its association with cognitive function in a rural elderly cohort: the MoVIES project. Monongahela Valley independent elders survey. Am J Epidemiol 1998, 148:38-44.

178. Morris MC, Beckett LA, Scherr PA, Hebert LE, Bennett DA, Field TS, Evans DA: Vitamin $\mathrm{E}$ and vitamin $\mathrm{C}$ supplement use and risk of incident Alzheimer disease. Alzheimer Dis Assoc Disord 1998, 12:121-126.

179. Schmidt R, Hayn M, Reinhart B, Roob G, Schmidt H, Schumacher M, Watzinger N, Launer L: Plasma antioxidants and cognitive performance in middle-aged and older adults: results of the Austrian stroke prevention study. J Am Geriatr Soc 1998, 46:1407-1410.

180. Masaki KH, Losonczy KG, Izmirlian G, Foley DJ, Ross GW, Petrovitch H, Havlik $R$, White LR: Association of vitamin $E$ and $C$ supplement use with cognitive function and dementia in elderly men. Neurology 2000, 54:1265-1272

181. Peacock JM, Folsom AR, Knopman DS, Mosley TH, Goff DC Jr, Szklo M: Dietary antioxidant intake and cognitive performance in middle-aged adults. The Atherosclerosis Risk in Communities (ARIC) Study investigators. Public Health Nutr 2000, 3:337-343.

182. Engelhart MJ, Geerlings MI, Ruitenberg A, van Swieten JC, Hofman A, Witteman JC, Breteler MM: Dietary intake of antioxidants and risk of Alzheimer disease. JAMA 2002, 287:3223-3229.

183. Morris MC, Evans DA, Bienias JL, Tangney CC, Bennett DA, Aggarwal N, Wilson RS, Scherr PA: Dietary intake of antioxidant nutrients and the risk of incident Alzheimer disease in a biracial community study. JAMA 2002, 287:3230-3237.

184. Morris MC, Evans DA, Bienias JL, Tangney CC, Wilson RS: Vitamin E and cognitive decline in older persons. Arch Neurol 2002, 59:1125-1132

185. Gray SL, Hanlon JT, Landerman LR, Artz M, Schmader KE, Fillenbaum GG: Is antioxidant use protective of cognitive function in the community-dwelling elderly? Am J Geriatr Pharmacother 2003, 1:3-10.

186. Grodstein F, Chen J, Willett WC: High-dose antioxidant supplements and cognitive function in community-dwelling elderly women. Am J Clin Nutr 2003, 77:975-984

187. Luchsinger JA, Tang MX, Shea S, Mayeux R: Antioxidant vitamin intake and risk of Alzheimer disease. Arch Neurol 2003, 60:203-208.

188. Laurin D, Masaki KH, Foley DJ, White LR, Launer $\sqcup$ : Midlife dietary intake of antioxidants and risk of late-life incident dementia: the Honolulu-Asia aging study. Am J Epidemiol 2004, 159:959-967.

189. Zandi PP, Anthony JC, Khachaturian AS, Stone SV, Gustafson D, Tschanz JT, Norton MC, Welsh-Bohmer KA, Breitner JC: Reduced risk of Alzheimer disease in users of antioxidant vitamin supplements: the Cache county study. Arch Neurol 2004, 61:82-88.

190. Cherubini A, Martin A, Andres-Lacueva C, Di lorio A, Lamponi M, Mecocci P, Bartali B, Corsi A, Senin U, Ferrucci L: Vitamin E levels, cognitive impairment and dementia in older persons: the InCHIANTI study. Neurobiol Aging 2005, 26:987-994

191. Engelhart MJ, Ruitenberg A, Meijer J, Kiliaan A, van Swieten JC, Hofman A, Witteman JC, Breteler MM: Plasma levels of antioxidants are not associated with Alzheimer's disease or cognitive decline. Dement Geriatr Cogn Disord 2005, 19:134-139.
192. Fillenbaum GG, Kuchibhatla MN, Hanlon JT, Artz MB, Pieper CF, Schmader KE, Dysken MW, Gray SL: Dementia and Alzheimer's disease in community-dwelling elders taking vitamin C and/or vitamin E. Ann Pharmacother 2005, 39:2009-2014.

193. Maxwell CJ, Hicks MS, Hogan DB, Basran J, Ebly EM: Supplemental use of antioxidant vitamins and subsequent risk of cognitive decline and dementia. Dement Geriatr Cogn Disord 2005, 20:45-51.

194. Morris MC, Evans DA, Tangney CC, Bienias JL, Wilson RS, Aggarwal NT, Scherr PA: Relation of the tocopherol forms to incident Alzheimer disease and to cognitive change. Am J Clin Nutr 2005, 81:508-514

195. Akbaraly NT, Faure H, Gourlet V, Favier A, Berr C: Plasma carotenoid levels and cognitive performance in an elderly population: results of the EVA study. J Gerontol A Biol Sci Med Sci 2007, 62:308-316.

196. Dunn JE, Weintraub S, Stoddard AM, Banks S: Serum alpha-tocopherol, concurrent and past vitamin $E$ intake, and mild cognitive impairment Neurology 2007, 68:670-676.

197. Wengreen HJ, Munger RG, Corcoran CD, Zandi P, Hayden KM, Fotuhi M, Skoog I, Norton MC, Tschanz J, Breitner JC, Welsh-Bohmer KA: Antioxidant intake and cognitive function of elderly men and women: the Cache county study. J Nutr Health Aging 2007, 11:230-237.

198. Fotuhi M, Zandi PP, Hayden KM, Khachaturian AS, Szekely CA, Wengreen H, Munger RG, Norton MC, Tschanz JT, Lyketsos CG, Breitner JC, Welsh-Bohmer $K$ : Better cognitive performance in elderly taking antioxidant vitamins $E$ and $C$ supplements in combination with nonsteroidal anti-inflammatory drugs: the Cache county study. Alzheimers Dement 2008, 4:223-227.

199. Gray SL, Anderson ML, Crane PK, Breitner JC, McCormick W, Bowen JD, Teri L, Larson E: Antioxidant vitamin supplement use and risk of dementia or Alzheimer's disease in older adults. J Am Geriatr Soc 2008, 56:291-295.

200. Ravaglia G, Forti P, Lucicesare A, Pisacane N, Rietti E, Mangialasche F, Cecchetti R, Patterson C, Mecocci P: Plasma tocopherols and risk of cognitive impairment in an elderly Italian cohort. Am J Clin Nutr 2008, 87:1306-1313.

201. Devore EE, Kang JH, Stampfer MJ, Grodstein F: Total antioxidant capacity of diet in relation to cognitive function and decline. Am J Clin Nutr 2010 92:1157-1164

202. McNeill G, Jia X, Whalley LJ, Fox HC, Corley J, Gow AJ, Brett CE, Starr JM, Deary IJ: Antioxidant and $B$ vitamin intake in relation to cognitive function in later life in the Lothian birth cohort 1936. Eur J Clin Nutr 2011, 65:619-626.

203. Kalmijn S, Launer $\amalg$, Lindemans J, Bots ML, Hofman A, Breteler MM: Total homocysteine and cognitive decline in a community-based sample of elderly subjects: the Rotterdam study. Am J Epidemiol 1999, 150:283-289.

204. Duthie SJ, Whalley LJ, Collins AR, Leaper S, Berger K, Deary IJ: Homocysteine, B vitamin status, and cognitive function in the elderly. Am J Clin Nutr 2002, 75:908-913.

205. Prins ND, Den Heijer T, Hofman A, Koudstaal PJ, Jolles J, Clarke R, Breteler MM: Homocysteine and cognitive function in the elderly: the Rotterdam scan study. Neurology 2002, 59:1375-1380.

206. Seshadri S, Beiser A, Selhub J, Jacques PF, Rosenberg IH, D'Agostino RB, Wilson PW, Wolf PA: Plasma homocysteine as a risk factor for dementia and Alzheimer's disease. N Engl J Med 2002, 346:476-483.

207. Miller JW, Green R, Ramos MI, Allen LH, Mungas DM, Jagust WJ, Haan MN: Homocysteine and cognitive function in the Sacramento area Latino study on aging. Am J Clin Nutr 2003, 78:441-447.

208. Ravaglia G, Forti P, Maioli F, Muscari A, Sacchetti L, Arnone G, Nativio V, Talerico T, Mariani E: Homocysteine and cognitive function in healthy elderly community dwellers in Italy. Am J Clin Nutr 2003, 77:668-673.

209. Luchsinger JA, Tang MX, Shea S, Miller J, Green R, Mayeux R: Plasma homocysteine levels and risk of Alzheimer disease. Neurology 2004, 62:1972-1976.

210. Ariogul S, Cankurtaran M, Dagli N, Khalil M, Yavuz B: Vitamin B12, folate, homocysteine and dementia: are they really related? Arch Gerontol Geriatr 2005, 40:139-146.

211. Campbell AK, Jagust WJ, Mungas DM, Miller JW, Green R, Haan MN, Allen LH: Low erythrocyte folate, but not plasma vitamin B-12 or homocysteine, is associated with dementia in elderly Latinos. J Nutr Health Aging 2005, 9:39-43.

212. Elias MF, Sullivan LM, D'Agostino RB, Elias PK, Jacques PF, Selhub J, Seshadri S, Au R, Beiser A, Wolf PA: Homocysteine and cognitive performance in the Framingham offspring study: age is important. Am J Epidemiol 2005, 162:644-653. 
213. Kado DM, Karlamangla AS, Huang MH, Troen A, Rowe JW, Selhub J, Seeman TE: Homocysteine versus the vitamins folate, $\mathrm{B} 6$, and $\mathrm{B} 12$ as predictors of cognitive function and decline in older high-functioning adults: MacArthur studies of successful aging. Am J Med 2005, 118:161-167.

214. Mooijaart SP, Gussekloo J, Frolich M, Jolles J, Stott DJ, Westendorp RG, de Craen AJ: Homocysteine, vitamin B-12, and folic acid and the risk of cognitive decline in old age: the Leiden 85-Plus study. Am J Clin Nutr 2005, 82:866-871.

215. Quadri P, Fragiacomo C, Pezzati R, Zanda E, Tettamanti M, Lucca U: Homocysteine and $B$ vitamins in mild cognitive impairment and dementia. Clin Chem Lab Med 2005, 43:1096-1100.

216. Ramos MI, Allen LH, Mungas DM, Jagust WJ, Haan MN, Green R, Miller JW: Low folate status is associated with impaired cognitive function and dementia in the Sacramento area Latino study on aging. Am J Clin Nutr 2005, 82:1346-1352.

217. Ravaglia G, Forti P, Maioli F, Martelli M, Servadei L, Brunetti N, Porcellini E, Licastro F: Homocysteine and folate as risk factors for dementia and Alzheimer disease. Am J Clin Nutr 2005, 82:636-643.

218. Schafer JH, Glass TA, Bolla KI, Mintz M, Jedlicka AE, Schwartz BS: Homocysteine and cognitive function in a population-based study of older adults. J Am Geriatr Soc 2005, 53:381-388.

219. Tucker KL, Qiao N, Scott T, Rosenberg I, Spiro A 3rd: High homocysteine and low $B$ vitamins predict cognitive decline in aging men: the Veterans affairs normative aging study. Am J Clin Nutr 2005, 82:627-635.

220. Elias MF, Robbins MA, Budge MM, Elias PK, Brennan SL, Johnston C, Nagy Z, Bates CJ: Homocysteine, folate, and vitamins B6 and B12 blood levels in relation to cognitive performance: the Maine-Syracuse study. Psychosom Med 2006, 68:547-554

221. Feng L, Ng TP, Chuah L, Niti M, Kua EH: Homocysteine, folate, and vitamin B-12 and cognitive performance in older Chinese adults: findings from the Singapore longitudinal ageing study. Am J Clin Nutr 2006, 84:1506-1512

222. van Raamt AF, Kalmijn S, Mali WP, van Zandvoort MJ, van der Graaf $Y$ : Homocysteine level and cognitive function in patients with arterial disease: the second manifestations of ARTerial disease study. J Am Geriatr Soc 2006, 54:575-579.

223. Clarke R, Birks J, Nexo E, Ueland PM, Schneede J, Scott J, Molloy A, Evans JG: Low vitamin B-12 status and risk of cognitive decline in older adults. Am J Clin Nutr 2007, 86:1384-1391.

224. Haan MN, Miller JW, Aiello AE, Whitmer RA, Jagust WJ, Mungas DM, Allen $\mathrm{LH}$, Green R: Homocysteine, B vitamins, and the incidence of dementia and cognitive impairment: results from the Sacramento area Latino study on aging. Am J Clin Nutr 2007, 85:511-517.

225. Kim J, Park MH, Kim E, Han C, Jo SA, Jo I: Plasma homocysteine is associated with the risk of mild cognitive impairment in an elderly Korean population. J Nutr 2007, 137:2093-2097.

226. Elias MF, Robbins MA, Budge MM, Elias PK, Dore GA, Brennan SL, Johnston C, Nagy Z: Homocysteine and cognitive performance: modification by the ApoE genotype. Neurosci Lett 2008, 430:64-69.

227. Kim JM, Kim SW, Shin IS, Yang SJ, Park WY, Kim SJ, Shin HY, Yoon JS: Folate, vitamin $b(12)$, and homocysteine as risk factors for cognitive decline in the elderly. Psychiatry Investig 2008, 5:36-40.

228. Kim JM, Stewart R, Kim SW, Shin IS, Yang SJ, Shin HY, Yoon JS: Changes in folate, vitamin B12 and homocysteine associated with incident dementia. J Neurol Neurosurg Psychiatry 2008, 79:864-868.

229. Reitz C, Tang MX, Miller J, Green R, Luchsinger JA: Plasma homocysteine and risk of mild cognitive impairment. Dement Geriatr Cogn Disord 2009, 27:11-17.

230. Redeen S, Ryberg A, Petersson F, Eriksson O, Nagga K, Borch K: Homocysteine levels in chronic gastritis and other conditions: relations to incident cardiovascular disease and dementia. Dig Dis Sci 2010, 55:351-358

231. van den Kommer TN, Dik MG, Comijs HC, Jonker C, Deeg DJ: Homocysteine and inflammation: predictors of cognitive decline in older persons? Neurobiol Aging 2010, 31:1700-1709.

232. Perneczky R, Alexopoulos $P$, Kurz A, Bickel $H$ : Cognitive reserve, homocysteine, and cognition in the Bavarian school sisters study. J Am Geriatr Soc 2011, 59:1754-1756.

233. Zylberstein DE, Lissner $L$, Bjorkelund $C$, Mehlig $K$, Thelle DS, Gustafson D, Ostling S, Waern M, Guo X, Skoog I: Midlife homocysteine and late-life dementia in women. A prospective population study. Neurobiol Aging 2011, 32:380-386.
234. Ford AH, Flicker L, Alfonso H, Hankey GJ, Norman PE, van Bockxmeer FM, Almeida OP: Plasma homocysteine and MTHFRC677T polymorphism as risk factors for incident dementia. J Neurol Neurosurg Psychiatry 2012, 83:70-75.

235. Ford AH, Flicker L, Hankey GJ, Norman P, van Bockxmeer FM, Almeida OP: Homocysteine, methylenetetrahydrofolate reductase C677T polymorphism and cognitive impairment: the health in men study. Mol Psychiatry 2012, 17:559-566.

236. Kalmijn S, Feskens EJ, Launer $\amalg$, Kromhout D: Polyunsaturated fatty acids, antioxidants, and cognitive function in very old men. Am J Epidemiol 1997, 145:33-41.

237. Kalmijn S, Launer $\sqcup$, Ott A, Witteman JC, Hofman A, Breteler MM: Dietary fat intake and the risk of incident dementia in the Rotterdam study. Ann Neurol 1997, 42:776-782.

238. Engelhart MJ, Geerlings MI, Ruitenberg A, Van Swieten JC, Hofman A, Witteman JC, Breteler MM: Diet and risk of dementia: does fat matter?: the Rotterdam study. Neurology 2002, 59:1915-1921.

239. Morris MC, Evans DA, Bienias JL, Tangney CC, Bennett DA, Wilson RS, Aggarwal N, Schneider J: Consumption of fish and n-3 fatty acids and risk of incident Alzheimer disease. Arch Neurol 2003, 60:940-946.

240. Kalmijn S, van Boxtel MP, Ocke M, Verschuren WM, Kromhout D, Launer LJ: Dietary intake of fatty acids and fish in relation to cognitive performance at middle age. Neurology 2004, 62:275-280.

241. Morris MC, Evans DA, Tangney CC, Bienias JL, Wilson RS: Fish consumption and cognitive decline with age in a large community study. Arch Neurol 2005, 62(12):1849-53.

242. Barberger-Gateau P, Raffaitin C, Letenneur L, Berr C, Tzourio C, Dartigues JF, Alperovitch A: Dietary patterns and risk of dementia: the Three-City cohort study. Neurology 2007, 69:1921-1930.

243. Beydoun MA, Kaufman JS, Satia JA, Rosamond W, Folsom AR: Plasma n-3 fatty acids and risk of cognitive decline among older adults: the atherosclerosis risk in communities (ARIC) study. Am J Clin Nutr 2007, 84(4):1103-11. In press.

244. Cherubini A, Andres-Lacueva C, Martin A, Lauretani F, lorio AD, Bartali B, Corsi A, Bandinelli S, Mattson MP, Ferrucci L: Low plasma N-3 fatty acids and dementia in older persons: the InCHIANTI study. J Gerontol A Bio/ SC Med Sci 2007, 62:1120-1126.

245. Dullemeijer C, Durga J, Brouwer IA, van de Rest O, Kok FJ, Brummer RJ, van Boxtel MP, Verhoef P: $\mathrm{n} 3$ fatty acid proportions in plasma and cognitive performance in older adults. Am J Clin Nutr 2007, 86:1479-1485.

246. Beydoun MA, Kaufman JS, Sloane PD, Heiss G, Ibrahim J: n-3 Fatty acids, hypertension and risk of cognitive decline among older adults in the atherosclerosis risk in communities (ARIC) study. Public Health Nutr 2008, 11:17-29.

247. Eskelinen MH, Ngandu T, Helkala EL, Tuomilehto J, Nissinen A, Soininen $H$, Kivipelto M: Fat intake at midlife and cognitive impairment later in life: a population-based CAIDE study. Int J Geriatr Psychiatry 2008, 23:741-747

248. Samieri C, Feart C, Letenneur L, Dartigues JF, Peres K, Auriacombe S, Peuchant E, Delcourt C, Barberger-Gateau P: Low plasma eicosapentaenoic acid and depressive symptomatology are independent predictors of dementia risk. Am J Clin Nutr 2008, 88:714-721.

249. Albanese E, Dangour AD, Uauy R, Acosta D, Guerra M, Guerra SS, Huang Y, Jacob KS, de Rodriguez JL, Noriega LH, Salas A, Sosa AL, Sousa RM, Williams J, Ferri $C P$, Prince MJ: Dietary fish and meat intake and dementia in Latin America, China, and India: a 10/66 dementia research group population-based study. Am J Clin Nutr 2009, 90:392-400.

250. Devore EE, Grodstein F, van Rooij FJ, Hofman A, Rosner B, Stampfer MJ, Witteman JC, Breteler MM: Dietary intake of fish and omega-3 fatty acids in relation to long-term dementia risk. Am J Clin Nutr 2009, 90:170-176

251. Kroger E, Verreault R, Carmichael PH, Lindsay J, Julien P, Dewailly E, Ayotte $P$, Laurin D: Omega-3 fatty acids and risk of dementia: the Canadian study of health and aging. Am J Clin Nutr 2009, 90:184-192.

252. van de Rest O, Spiro A 3rd, Krall-Kaye E, Geleijnse JM, de Groot LC, Tucker $\mathrm{KL}$ : Intakes of $(n-3)$ fatty acids and fatty fish are not associated with cognitive performance and 6-year cognitive change in men participating in the Veterans affairs normative aging study. J Nutr 2009, 139:2329-2336.

253. Vercambre MN, Boutron-Ruault MC, Ritchie K, Clavel-Chapelon F, Berr C: Long-term association of food and nutrient intakes with cognitive and 
functional decline: a 13-year follow-up study of elderly French women. Br J Nutr 2009, 102:419-427.

254. Gonzalez S, Huerta JM, Fernandez S, Patterson AM, Lasheras C: The relationship between dietary lipids and cognitive performance in an elderly population. Int J Food Sci Nutr 2010, 61:217-225.

255. Muldoon MF, Ryan CM, Sheu L, Yao JK, Conklin SM, Manuck SB: Serum phospholipid docosahexaenonic acid is associated with cognitive functioning during middle adulthood. J Nutr 2010, 140:848-853.

256. Gao Q, Niti M, Feng L, Yap KB, Ng TP: Omega-3 polyunsaturated fatty acid supplements and cognitive decline: Singapore longitudinal aging studies. J Nutr Health Aging 2011, 15:32-35.

257. Kesse-Guyot E, Peneau S, Ferry M, Jeandel C, Hercberg S, Galan P: Thirteen-year prospective study between fish consumption, long-chain $n-3$ fatty acids intakes and cognitive function. J Nutr Health Aging 2011, 15:115-120.

258. Samieri C, Feart C, Proust-Lima C, Peuchant E, Dartigues JF, Amieva H, Barberger-Gateau P: omega-3 fatty acids and cognitive decline: modulation by ApoEepsilon4 allele and depression. Neurobiol Aging 2011, 32:2317. e2313-2322.

259. Thomson TM: Endnote X3. Philadelphia, PA: Thomson Reuters; 2010.

260. Petitti DB: Statistical methods in meat-analysis. In Meta-analysis. Decision Analysis, and cost-effectiveness analysis. 2000th edition. Edited by Petitti DB. New York, NY: Oxford University Press; 2000.

261. Hildebrandt M, Bender R, Gehrmann U, Blettner M: Calculating confidence intervals for impact numbers. BMC Med Res Methodol 2006, 6:32.

262. Egger M, Smith GD, Altman DG: Systematic Reviews in heath care: Meta-analysis in context. 2nd edition. London. UK: the BMJ Publishing Group; 2001.

263. Egger M, Smith GD, Schneider M, Minder C: Bias in meta-analysis detected by a simple, graphical test. BMJ 1997, 315:629-634.

264. Begg CB, Mazumdar M: Operating characteristics of a rank correlation test for publication bias. Biometrics 1994, 50:1088-1101.

265. Egger M, Davey Smith G, Schneider M, Minder C, Davey Smith G, Schneider $M$, Minder C: Bias in meta-analysis detected by a simple, graphical test. BMJ 1997, 315:629-634.

266. STATA: Statistics/Data Analysis: Release 11.0. In Book Statistics/Data Analysis: Release 11.0. Edited by Editor ed. City: Stata Corporation; 2009

267. Albert MS: How does education affect cognitive function? Ann Epidemiol 1995, 5:76-78

268. Wilson RS, Bennett DA, Beckett LA, Morris MC, Gilley DW, Bienias JL, Scherr $P A$, Evans DA: Cognitive activity in older persons from a geographically defined population. J Gerontol B Psychol Sci Soc Sci 1999, 54:P155-160.

269. Gorelick PB, Sacco RL, Smith DB, Alberts M, Mustone-Alexander L, Rader D, Ross JL, Raps E, Ozer MN, Brass LM, Malone ME, Goldberg S, Booss J, Hanley DF, Toole JF, Greengold NL, Rhew DC: Prevention of a first stroke: a review of guidelines and a multidisciplinary consensus statement from the National Stroke Association. JAMA 1999, 281:1112-1120.

270. Markesbery WR, Carney JM: Oxidative alterations in Alzheimer's disease. Brain Pathol 1999, 9:133-146.

271. Kellar KJ, Wonnacott S (Eds): Nicotinic cholinergic receptors in Alzheimer's disease, in nicotine psychopharmacology: molecular, cellular, and behavioral aspects. Oxford: Oxford University Press; 1990.

272. Nordberg A: Biological markers and the cholinergic hypothesis in Alzheimer's disease. Acta Neurol Scand Suppl 1992, 139:54-58.

273. Letenneur L, Larrieu S, Barberger-Gateau P: Alcohol and tobacco consumption as risk factors of dementia: a review of epidemiological studies. Biomed Pharmacother 2004, 58:95-99.

274. Rogers RL, Meyer JS, Mortel KF: After reaching retirement age physical activity sustains cerebral perfusion and cognition. J Am Geriatr Soc 1990 38:123-128.

275. Dustman RE, Ruhling RO, Russell EM, Shearer DE, Bonekat HW, Shigeoka JW, Wood JS, Bradford DC: Aerobic exercise training and improved neuropsychological function of older individuals. Neurobiol Aging 1984 5:35-42.

276. Spirduso WW: Physical fitness, aging, and psychomotor speed: a review. J Gerontol 1980, 35:850-865.

277. Gomez-Pinilla F, Dao L, So V: Physical exercise induces FGF-2 and its mRNA in the hippocampus. Brain Res 1997, 764:1-8.

278. Cotman CW, Engesser-Cesar C: Exercise enhances and protects brain function. Exerc Sport Sci Rev 2002, 30:75-79.

279. Pignatti F, Rozzini R, Trabucchi M: Physical activity and cognitive decline in elderly persons. Arch Intern Med 2002, 162:361-362.
280. James JE: Caffeine \& health. London, England: Academic; 1991.

281. Battig K, Buzzi R: Effect of coffee on the speed of subject-paced information processing. Neuropsychobiology 1986, 16:126-130.

282. Riedel W, Hogervorst E, Leboux R, Verhey F, van Praag H, Jolles J: Caffeine attenuates scopolamine-induced memory impairment in humans. Psychopharmacology (Berl) 1995, 122:158-168.

283. Behl C: Amyloid beta-protein toxicity and oxidative stress in Alzheimer's disease. Cell Tissue Res 1997, 290:471-480

284. Christen Y: Oxidative stress and Alzheimer disease. Am J Clin Nutr 2000 71:621S-629S

285. Grundman M: Vitamin E and Alzheimer disease: the basis for additional clinical trials. Am J Clin Nutr 2000, 71:630S-636S.

286. Refsum H, Ueland PM, Nygard O, Vollset SE: Homocysteine and cardiovascular disease. Annu Rev Med 1998, 49:31-62.

287. Garcia A, Haron Y, Pulman K, Hua L, Freedman M: Increases in homocysteine are related to worsening of stroop scores in healthy elderly persons: a prospective follow-up study. J Gerontol A Biol Sci Med Sci 2004, 59:1323-1327.

288. Teunissen CE, Blom AH, Van Boxtel MP, Bosma H, de Bruijn C, Jolles J, Wauters BA, Steinbusch HW, de Vente J: Homocysteine: a marker for cognitive performance? A longitudinal follow-up study. J Nutr Health Aging 2003, 7:153-159

289. Scott TM, Tucker KL, Bhadelia A, Benjamin B, Patz S, Bhadelia R, Liebson E, Price LL, Griffith J, Rosenberg I, Folstein MF: Homocysteine and B vitamins relate to brain volume and white-matter changes in geriatric patients with psychiatric disorders. Am J Geriatr Psychiatry 2004, 12:631-638.

290. Dufouil C, Alperovitch A, Ducros V, Tzourio C: Homocysteine, white matter hyperintensities, and cognition in healthy elderly people. Ann Neurol 2003, 53:214-221.

291. Sachdev PS, Valenzuela M, Wang XL, Looi JC, Brodaty H: Relationship between plasma homocysteine levels and brain atrophy in healthy elderly individuals. Neurology 2002, 58:1539-1541.

292. Bleich S, Kornhuber J: Relationship between plasma homocysteine levels and brain atrophy in healthy elderly individuals. Neurology 2003, 60:1220 author reply 1220 .

293. den Heijer T, Vermeer SE, Clarke R, Oudkerk M, Koudstaal PJ, Hofman A, Breteler MM: Homocysteine and brain atrophy on MRI of non-demented elderly. Brain 2003, 126:170-175.

294. Bottiglieri T: Homocysteine and folate metabolism in depression. Prog Neuropsychopharmacol Biol Psychiatry 2005, 29:1 103-1112.

295. Selhub J, Jacques PF, Wilson PW, Rush D, Rosenberg IH: Vitamin status and intake as primary determinants of homocysteinemia in an elderly population. JAMA 1993, 270:2693-2698.

296. Li L, Cao D, Desmond R, Rahman A, Lah JJ, Levey Al, Zamrini E: Cognitive performance and plasma levels of homocysteine, vitamin B12, folate and lipids in patients with Alzheimer disease. Dement Geriatr Cogn Disord 2008, 26:384-390.

297. Vidal JS, Dufouil C, Ducros V, Tzourio C: Homocysteine, folate and cognition in a large community-based sample of elderly people-the $3 C$ Dijon Study. Neuroepidemiology 2008, 30:207-214.

298. Kruman II, Culmsee C, Chan SL, Kruman Y, Guo Z, Penix L, Mattson MP: Homocysteine elicits a DNA damage response in neurons that promotes apoptosis and hypersensitivity to excitotoxicity. J Neurosci 2000, 20:6920-6926.

299. Parsons RB, Waring RH, Ramsden DB, Williams AC: In vitro effect of the cysteine metabolites homocysteic acid, homocysteine and cysteic acid upon human neuronal cell lines. Neurotoxicology 1998, 19:599-603.

300. Arab L: Biomarkers of fat and fatty acid intake. J Nutr 2003, 133(Suppl 3):925S-932S.

301. Andreassi M, Forleo P, Di Lorio A, Masci S, Abate G, Amerio P: Efficacy of gamma-linolenic acid in the treatment of patients with atopic dermatitis. $J$ Int Med Res 1997, 25:266-274.

302. Cerolini S, Kelso KA, Noble RC, Speake BK, Pizzi F, Cavalchini LG: Relationship between spermatozoan lipid composition and fertility during aging of chickens. Biol Reprod 1997, 57:976-980.

303. Zhang $L:$ The effects of essential fatty acids preparation in the treatment of intrauterine growth retardation. Am J Perinatol 1997, 14:535-537.

304. Bjerve KS: Omega 3 fatty acid deficiency in man: implications for the requirement of alpha-linolenic acid and long-chain omega 3 fatty acids. World Rev Nutr Diet 1991, 66:133-142. 
305. Wainwright PE: Dietary essential fatty acids and brain function: a developmental perspective on mechanisms. Proc Nutr Soc 2002, 61:61-69. 306. Haag M: Essential fatty acids and the brain. Can J Psychiatry 2003, 48:195-203

307. de Wilde MC, Hogyes E, Kiliaan AJ, Farkas T, Luiten PG, Farkas E: Dietary fatty acids alter blood pressure, behavior and brain membrane composition of hypertensive rats. Brain Res 2003, 988:9-19.

doi:10.1186/1471-2458-14-643

Cite this article as: Beydoun et al:: Epidemiologic studies of modifiable factors associated with cognition and dementia: systematic review and meta-analysis. BMC Public Health 2014 14:643.

\section{Submit your next manuscript to BioMed Central and take full advantage of:}

- Convenient online submission

- Thorough peer review

- No space constraints or color figure charges

- Immediate publication on acceptance

- Inclusion in PubMed, CAS, Scopus and Google Scholar

- Research which is freely available for redistribution 